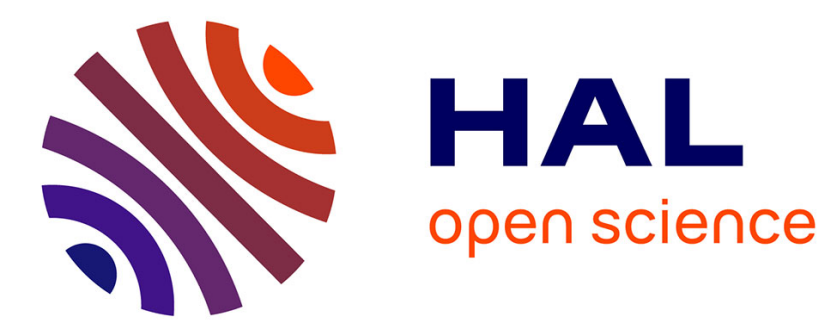

\title{
Efficiency-optimal power partitioning for improved partial load efficiency of electric drives
}

Olivier Béthoux, Eric Laboure, Ghislain Remy, Éric Berthelot

\section{To cite this version:}

Olivier Béthoux, Eric Laboure, Ghislain Remy, Éric Berthelot. Efficiency-optimal power partitioning for improved partial load efficiency of electric drives. Electric Power Systems Research, 2017, Electric Power Systems Research, 142, pp.176 - 189. 10.1016/j.epsr.2016.09.014 . hal-01385052

\section{HAL Id: hal-01385052 https://hal.science/hal-01385052}

Submitted on 24 Oct 2016

HAL is a multi-disciplinary open access archive for the deposit and dissemination of scientific research documents, whether they are published or not. The documents may come from teaching and research institutions in France or abroad, or from public or private research centers.
L'archive ouverte pluridisciplinaire HAL, est destinée au dépôt et à la diffusion de documents scientifiques de niveau recherche, publiés ou non, émanant des établissements d'enseignement et de recherche français ou étrangers, des laboratoires publics ou privés. 


\section{Accepted Manuscript}

Efficiency-optimal power partitioning for improved partial load efficiency of electric drives

Olivier Béthoux, Eric Labouré, Ghislain Remy, Eric Berthelot

DOI:

10.1016/j.epsr.2016.09.014

Reference:

Publisher:

ELSEVIER

To appear in:

Electric Power Systems Research

Received date:

2 March 2016

Revised date:

26 August 2016

Accepted date:

17 September 2016

Date of Publication: January 2017 (Volume 142, Pages 176-189)

Please cite this article as: Olivier Bethoux, Eric Laboure, Ghislain Remy, Eric Berthelot, Efficiency-optimal power partitioning for improved partial load efficiency of electric drives, Electric Power Systems Research, Volume 142, January 2017, Pages 176-189, ISSN 0378-7796, http://dx.doi.org/10.1016/j.epsr.2016.09.014.

Document Version: Early version, also known as pre-print

This is a PDF file of an unedited manuscript that has been accepted for publication. As a service to our customers we are providing this early version of the manuscript. The manuscript will undergo copyediting, typesetting, and review of the resulting proof before it is published in its final form. Please note that during the production process errors may be discovered which could affect the content, and all legal disclaimers that apply to the journal pertain. 
Accepted article for publication in a future issue of ELSEVIER Electric Power Systems Research - Citation information: 10.1016/j.epsr.2016.09.014.

\section{Efficiency-optimal power partitioning for}

\section{improved partial load efficiency of electric}

\section{drives}

CORRESPONDING AUTHOR: Olivier BETHOUX, Associate Professor, Univ Paris-Sud, France Affiliation: GeePs | Group of electrical engineering - Paris

Email: olivier.bethoux@,centralesupelec.fr

Tel: $+33(0) 169851656$

Fax: $+33(0) 169418318$

\section{Abstract}

In this paper, the global power conversion efficiency is improved for a fault-tolerant drive architecture. The fault-tolerant architecture is obtained by combination of a 3-phase open-end winding machine and a $3 \mathrm{H}-$ bridge inverter. This combination offers more degrees of freedom for 
Accepted article for publication in a future issue of ELSEVIER Electric Power Systems Research - Citation information: 10.1016/j.epsr.2016.09.014.

1 the control strategy than a classical 3-leg inverter. This paper demonstrates that the additional

2 degree of freedom of this power system can be exploited for efficiency optimization purposes in

3 normal operation mode. In the present work, the retained optimization criteria is the minimization

4 of the drive losses which is a critical issue. In addition, to fulfill the torque demand, this leads to a 5 constrained optimization problem which can be analytically solved using the Lagrange

6 multipliers method. Besides, as each motor phase can be driven independently, the resolutions for

7 three strategies, i.e. for three, two or one-phase simultaneous conduction of the inverter, provide

8 three different optimal current waveforms. This is the key point of the proposed efficiency-

9 optimal power partitioning for improved partial load efficiency of electric drives. Finally, on a

10 test bench, the real-time tracking of the mentioned current waveforms is successfully tested and

11 power measurements confirm the possibility of using the three different control strategies to

12 realize an efficiency optimum phase-shedding strategy.

13 KEYWORDS

14 Inverters, motor drives, permanent-magnet (PM) machines, losses minimization, efficiency15 optimal partitioning of the power, Lagrange multipliers method.

\section{INTRODUCTION}

18 Efficiency improvement in energy conversion process is becoming a primary development goal

19 in many applications, in connection with rising energy prices and resources conservation. This is,

20 in particular, the case in various areas such as embedded applications [1], communication 21 networks [2], data centers [3], electric grid generation [4-6], or automotive applications [7]. The

22 following part reviews best practices for enhancing the power converter efficiency for electric 23 drives. Some efficient techniques can be found in the power converters for photovoltaic systems 
Accepted article for publication in a future issue of ELSEVIER Electric Power Systems Research - Citation information: 10.1016/j.epsr.2016.09.014.

1 mainly. Indeed, photovoltaic inverters achieved in 2015 a rated power efficiency higher than

$299 \%$, driven by the market demand. This significantly exceeds the reference value of $95 \%$ of

3 year 2000 [8-11]. Similarly, pushed by high standards [12], converter stages of telecom power

4 modules produce less than $1 \%$ of power losses at rated power [13]. Indeed, the clear requirement

5 of this application, in terms of compactness and reliability, involves high power density while

6 keeping a low operating temperature. Therefore, minimizing losses of power electronics systems

7 gains increasingly in importance and power conversion efficiency tends to be a key criteria

8 among the performance indices [14].

9 The rated power operating point is often used to define the performance of a system. However, in

10 case of energy optimization considerations, the typical mission profile has to be considered,

11 leading to assess the losses on different operating points [15]. This is particularly important for

12 achieving a relevant energy efficiency optimization [16]. As an example, PV inverter certification

13 requires not only full-load efficiency but also partial load values, namely at $10 \%, 20 \%$ and $50 \%$

14 of rated power [17].

15 Automotive applications also lead to a wide range of operating points [18]. In such applications,

16 it is clearly demonstrated that the powertrain losses must be reduced for low power and low 17 speed in order to increase the vehicle's autonomy [19]. For instance, to assess vehicles 18 powertrain efficiency, a realistic average driving cycle such as ARTEMIS is used [20]. There are

19 various ways of enhancing a power converter's efficiency: these include using new components

20 [6], more complex topologies enabling soft-switching [21], or modular design [22,23], new

21 designs with better integration [24], system considerations and innovative control procedures, e.g.

22 Differential Power Processing [3]. All these considerations mainly lead to a global approach [14], 
Accepted article for publication in a future issue of ELSEVIER Electric Power Systems Research - Citation information: 10.1016/j.epsr.2016.09.014.

1 e.g. of the optimization of the combination of the machine and the associated power electronics

2 converters.

3 For single-cell converters, it should be noted that high efficiency at partial load leads to a

4 significant increase of the performance of the system at full load [25]. Thus, partial load

5 efficiency improvement is very difficult to achieve for classical converter topologies. Indeed, an

6 efficiency of $90 \%$ at $10 \%$ partial load corresponds to a rated power efficiency of $99 \%$ under the

7 assumption of constant losses over the entire output power range.

8 Experiencing the difficulty in obtaining a flat efficiency curve has led to the alternative solution

9 of splitting a single converter into several smaller converters working in parallel [26]. The

10 number of operating cells is defined to optimize the global power efficiency. Indeed, some of

11 them can be disconnected and set off to improve efficiency when working at partial load.

12 Choosing the number of operating converters with regard to the demanded power ensures that

13 each subsystem works within a small power range around its best efficient operating point. This

14 established control procedure is known as Phase Shedding or efficiency-optimal partitioning [27].

15 Toyota uses this strategy to manage a $114 \mathrm{~kW}$ boost converter implemented in the hydrogen-

16 powered Mirai fuel cell electric vehicle (EV) [28]. The DC converter regulating the voltage

17 delivered by the fuel cell is made of 4 parallel legs. The associated control determines in real-

18 time the optimal number of cells to be used; this strategy leads to reduce the boost losses by ten

19 per cent at $15 \mathrm{~kW}$ operating point [28]. This design also induces significant system improvements

20 [25]: among the benefits, one could easily identify input and output current ripple reduction [29],

21 a better continuity of service and also a fast transient response if using multiphase interleaved dc-

22 dc converters, as in the case of the power management of microprocessors or double-data rate 
Accepted article for publication in a future issue of ELSEVIER Electric Power Systems Research - Citation information: 10.1016/j.epsr.2016.09.014.

1 (DDR) memory [30]. With the goal of reducing power loss, the aforementioned system

2 consideration has not yet been exploited in a motor drive.

3 Therefore the present paper applies a similar point of view to the approach in multiple parallel 4 converters $[8,27-30]$ to an electric motor drive designed to be fault-tolerant. This drive is the 5 combination of a three-phase open-end-winding permanent magnet synchronous machine 6 (PMSM) and a three-phase inverter made of three full H-bridges. This architecture has been 7 patented for EV powertrain by the VALEO group, a world's leading automotive supplier [31-34].

8 Similarly to other three-phase structures, like neutral leg inverter or additional leg inverter [35], 9 the VALEO patented option has the advantage of improved continuity of service due to its fault 10 tolerant capability. In contrast, this solution has proved to be multifunctional without any 11 additional device (i.e. electrical contactor), permitting EV traction [36, 37], battery charging [38], 12 power injection back to the grid during peak demand (vehicle to grid / V2G) and post-fault 13 operating mode $[39,40]$. These are key features for specific applications like the EV emerging 14 market. In traction mode, its key competitive advantage relies on its high degrees of freedom 15 [41]. Unlike the combination of a classical three-leg inverter connected with a star- or delta16 connected PMSM, each winding can be supplied independently. It makes the topology 17 intrinsically fault-tolerant. Additionally in normal mode, thanks to this feature, the drive control 18 can be operated using only one or two phases sequentially instead of three phases simultaneously.

19 This option allows the increase the power dynamically in one or two phases and to cancel the 20 power in the other phases. As the drive is running in normal mode, it opens up the possibility for 21 choosing the best windings dynamically in order to minimize losses, while achieving the 22 demanded torque. Thus, on an electric turn, each of the 3 phases converts power at the most 23 appropriate moment. 
Accepted article for publication in a future issue of ELSEVIER Electric Power Systems Research - Citation information: 10.1016/j.epsr.2016.09.014.

1 In short, this article develops a method for normal operating optimized with respect to motor

2 drive energy efficiency; the main idea consists in adjusting the number of phases in operation as a

3 function of the required mechanical torque in order to maximize the drive power efficiency at low

4 torque operating points. The paper is organized as follows. Section 2 addresses the optimized

5 motor phase current shape in the general framework of non-sinusoidal PMSM back-electromotive

6 force (back-emf). In section 3, the drive current optimization method is applied in the three cases

7 of one, two or three phases conducting simultaneously; in all these three cases, the phase current

8 is derived analytically. Section 4 presents experimental validations of the innovative strategy.

9 Finally, section 5 draws conclusions and perspectives of the suggested approach.

10

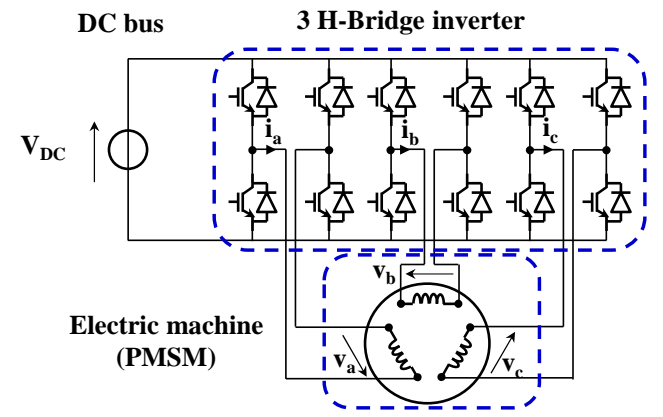

Fig. 1: 3-phase open-end winding architecture.

\section{DRIVE CuRRENT Optimization METHOD}

In the case of a sinusoidal magnetomotive force in a 3-phase synchronous machine, it is demonstrated that the optimal currents in the machine phases are sinusoidal and in phase with its electromotive forces [42]. These waveforms are, for a given electromagnetic torque, energetically optimal for the machine, as they minimize the RMS current values and hence the windings' Joule losses. In this case, cancellation of low frequency phase-voltage harmonics also enables the mitigation the machine ferromagnetic losses. 
Accepted article for publication in a future issue of ELSEVIER Electric Power Systems Research - Citation information: 10.1016/j.epsr.2016.09.014.

1 Now considering a more general drive current optimization, the design framework should

2 integrate both losses in the machine and the power inverter for a 3-phase, 2-phase or 1-phase

3 feeding sequence. In the following, any system loss will be taken into account.

4 A brief recall, underlying causes of losses in the machine-inverter association, allows better

5 understanding of the guiding principle in developing the proposed strategy, based on an

6 efficiency-optimal power partitioning (or fragmentation of power). The general problem of losses

7 minimization that can be stated in terms of a constrained problem can be solved using the

8 Lagrange multipliers method. The problem resolution using this method will be described at the

9 end of the section.

\subsection{Losses in the inverter and machine combination}

11 Three loss-types with characteristic dependence on the output power P_O are occurring for a

12 power electronic system [25]:

$$
P_{\text {losses }}=k_{0}+k_{1} \cdot P_{O}+k_{2} \cdot P_{O}^{2}
$$

13 The three parameters of this function are linked to various contributions:

$14 \quad 1 . k_{0}$ expresses the power losses, which are independent of output power. This means:

$212 . \quad k_{1}$ describes losses depending linearly on output power and is a consequence of: 
Accepted article for publication in a future issue of ELSEVIER Electric Power Systems Research - Citation information: 10.1016/j.epsr.2016.09.014.

- Conduction losses in power switches, since diodes and IGBT are mainly characterized by a threshold voltage;

- Switching losses in power switches.

3. $k_{2}$ defines losses with a quadratic dependency. This includes:

- Winding and DC capacitor Joule losses;

- Switch losses due to power switches' dynamic resistance.

7 Regarding the output power, system power efficiency is defined as:

$$
\eta=P_{O} /\left(P_{O}+P_{\text {losses }}\right)
$$

8 As results of (1), (2) yields an output power - efficiency curve starting from zero at a very small

9 output power, then increasing up to a maximum of $\eta_{\max }=1-k_{1}-2 \sqrt{k_{0} k_{2}}$

10 for $P_{O, \eta \max }=\sqrt{k_{0} / k_{2}}$ and finally decreasing for greater powers. The maximal efficiency point

$11 \eta_{\max }$ depends on the three aforementioned parameters $k_{0}, k_{1}$ and $k_{2}$.

12 In the case of several converters that can share the total power, it is possible to adjust these three

13 parameters. Indeed, regarding the same output power, using two converters instead of one has the 14 effect of:

15 1. Roughly doubling $k_{0}$ if only IGBT drivers and parasitic capacitances are considered;

162 . Leaving $k_{1}$ unchanged;

17 3. Halving $k_{2}$, in case of an equally partitioned power. In this situation $k_{0}^{\prime}=2 k_{0}$ and $k_{2}^{\prime}=$ $18 k_{2} / 2$ ), the best efficiency point $\eta_{\max }^{\prime}=\eta_{\max }$ remains unchanged but occurs at a 19 different operating point, namely an output power twice as large as the previous optimal power. Thus, by adjusting the number of converters in operation at the intersection of the efficiency curves, the resulting global power efficiency curve can be much flatter, leading to a wider high-efficiency range. 
Accepted article for publication in a future issue of ELSEVIER Electric Power Systems Research - Citation information: 10.1016/j.epsr.2016.09.014.

1 Indeed, for partial load conditions, as quadratic losses are low, it is more suitable to reduce the

2 constant factor $\left(k_{0}\right)$ by limiting the number of converters in operation. On the other hand, for

3 high current loads, it is worth using all the available converters in order to lower quadratic losses,

4 which have a significant impact. Fig. 2 provides a schematic overview of such a strategy in the

5 theoretical case of a converter made of two parallel cells. Each cell can be enabled or inhibited

6 depending on the delivered power. Fig. 3 provides a part of an INTERSIL datasheet device,

7 named ISL78225 [43]. It enables optimal control of a 4-phase DC/DC converter: the power

8 efficiency can reach a value higher than $95 \%$ over a wide power range $\left[\begin{array}{lll}I_{\text {rated }} / 7 & I_{\text {rated }}\end{array}\right]$.

9 This overview shows that with efficiency optimization goal, sharing the instantaneous power

10 between one, two or three phases is a pertinent degree of freedom to consider.

11

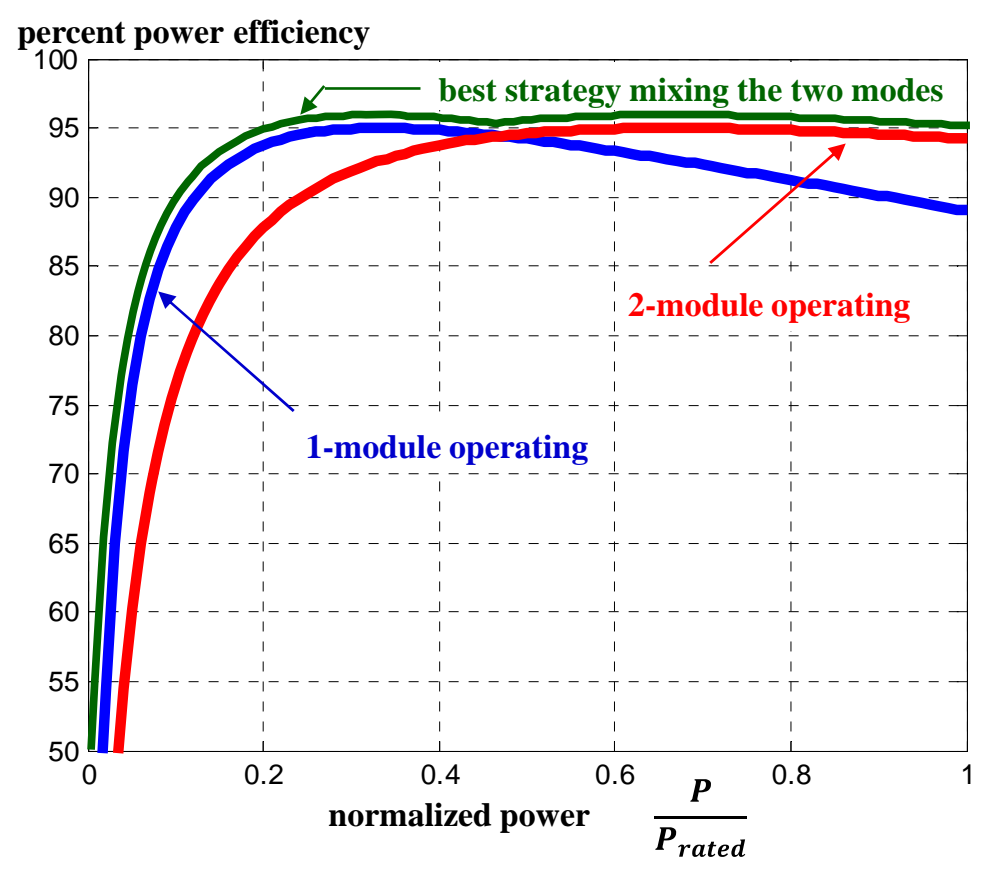

Fig. 2: 2-Module Power Converter efficiency regarding the strategy used. 
Accepted article for publication in a future issue of ELSEVIER Electric Power Systems Research - Citation information: 10.1016/j.epsr.2016.09.014.

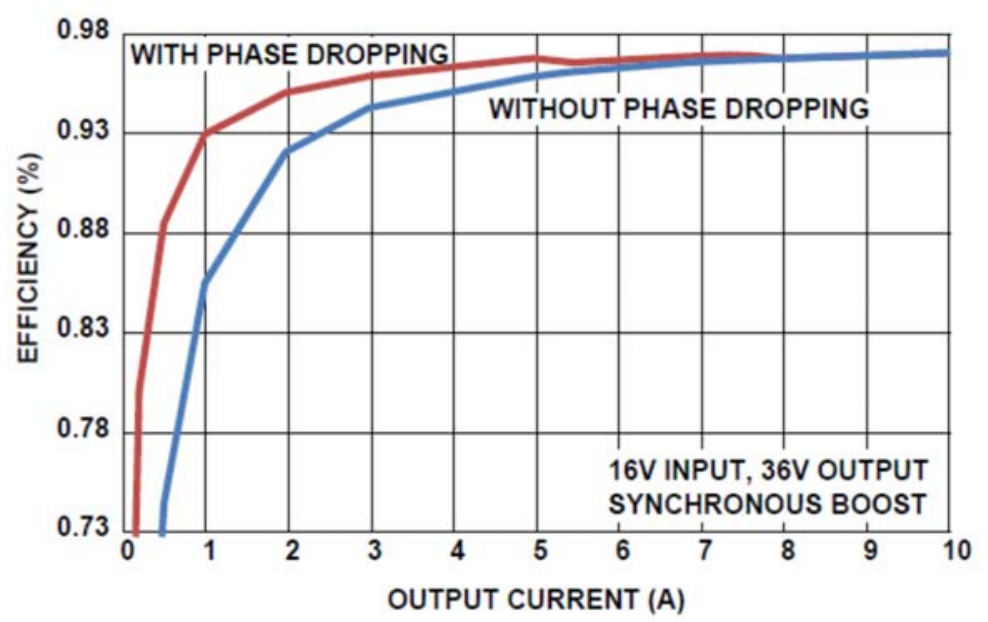

Fig. 3: 4-cell interleaved boost driven by ISL78225 control device (datasheet of INTERSIL [43]).

4 The main idea developed in this paper consists in extending this power partitioning principle to a 5 motor drive. The 3H-bridge topology of the inverter of this drive (Fig. 1) makes it possible to 6 operate on one, two or three phases of the machine. The power partitioning can therefore be 7 obtained by turning on successively, in synchronism with the rotor position,

- phase $a$, phase $b$ then phase $c$ for a one-phase operation

- phases $a, b$, phases $b, c$ then phases $c, a$ for two-phase operation

10 or by feeding, conventionally, the three phases of the machine continuously in case of three-

11 phase operation. For each configuration, an optimal phase-current waveform can be calculated to

12 maximize the global efficiency of the system. The waveforms can be analytically defined using

13 the Lagrange multipliers method.

\subsection{Method for determining optimal current waveform}

15 The aim is to shape the best current waveform in order to cancel torque ripple and achieve the 16 lowest losses in the inverter-machine combination. This dual objective can be translated as a 
Accepted article for publication in a future issue of ELSEVIER Electric Power Systems Research - Citation information: 10.1016/j.epsr.2016.09.014.

1 constraint of invariance in time of the instantaneous electromagnetic power (3) and the

2 minimization of the sum of the effective currents in the three drive phases (4).

$$
\begin{gathered}
P_{e m}=e_{a} \cdot i_{a}+e_{b} \cdot i_{b}+e_{c} \cdot i_{c} \\
\min \left(i_{a, R M S}+i_{b, R M S}+i_{c, R M S}\right)
\end{gathered}
$$

3 It is therefore a minimization problem (4) under a unique equality constraint (3) which can thus

4 be addressed using a single Lagrange multiplier $\lambda$. From a formal point of view, the three curves

5 specifying the three currents $i_{k}$ (with $k=a$ to $c$ ) over one electric revolution $\left(\theta_{e}\right)$ can be 6 considered as three functions (5) with a $[0 ; 2 \pi]$ domain of definition and an image in R.

$$
i_{k}:\left\{\begin{array}{llr}
{[0 ; 2 \pi]} & \rightarrow & \mathbb{R} \\
\theta_{e} & \mapsto i_{k}\left(\theta_{e}\right)
\end{array}\right.
$$

7 The equality constraint is related to a $f$ function implicitly dependent on $\theta_{e}$ :

$$
f\left(i_{a}, i_{b}, i_{c}\right)=e_{a} i_{a}+e_{b} i_{b}+e_{c} i_{c}-P_{e m}
$$

8 The performance criterion refers directly to a $J$ functional defined as:

$$
J: \begin{cases}\Omega & \rightarrow \\ g & \mapsto \int_{\theta_{i}=0}^{\theta_{f}=2 \pi} g\left(i_{a}\left(\theta_{e}\right), i_{b}\left(\theta_{e}\right), i_{c}\left(\theta_{e}\right)\right) \cdot d \theta_{e}\end{cases}
$$

9 Where $g$ is the function implicitly dependent on $\theta_{e}$ described as:

$$
g\left(i_{a}, i_{b}, i_{c}\right)=\left(i_{a}\right)^{2}+\left(i_{b}\right)^{2}+\left(i_{c}\right)^{2}
$$

10 The Lagrange method based on the calculus of variations requires to define a Lagrange function

$11 \lambda\left(\theta_{e}\right)$ and an extended functional $J_{e}[44-46]$ :

$$
J_{e}\left(i_{a}, i_{b}, i_{c}, \lambda\right)=\int_{\theta_{i}=0}^{\theta_{f}=2 \pi}\left\{g\left(i_{a}, i_{b}, i_{c}\right)+\lambda f\left(i_{a}, i_{b}, i_{c}\right)\right\} d \theta
$$

12 A necessary condition for finding four consistent curves $i_{a}\left(\theta_{e}\right), i_{b}\left(\theta_{e}\right), i_{a}\left(\theta_{e}\right)$ and $\lambda\left(\theta_{e}\right)$ is to 13 cancel functional derivative of $J_{e}$. This lead to satisfy the set of 4 equations: 
Accepted article for publication in a future issue of ELSEVIER Electric Power Systems Research - Citation information: 10.1016/j.epsr.2016.09.014.

$$
\left\{\begin{array}{c}
\frac{\partial g_{e}}{\partial i_{a}}=2 \cdot i_{a}+\lambda \cdot e_{a}=0 \\
\frac{\partial g_{e}}{\partial i_{b}}=2 \cdot i_{b}+\lambda \cdot e_{b}=0 \\
\frac{\partial g_{e}}{\partial i_{c}}=2 \cdot i_{c}+\lambda \cdot e_{c}=0 \\
f=e_{a} \cdot i_{a}+e_{b} \cdot i_{b}+e_{c} \cdot i_{c}-P_{e m}=0
\end{array}\right.
$$

1 Where the extended function is defined as: $g_{e}=g+\lambda f$.

2 Solving this Euler-Lagrange equation obtains the phase-current shapes. The following section

3 gives the results for the three modes mentioned previously in the introduction of section 2 and

4 evaluates their performances against the conventional three-phase sinusoidal mode.

\section{Optimal CurRent WAVEForm For The 3 Modes}

6 Based on the consideration defined above, the phase-current shapes can be calculated for the

7 three suggested modes. To demonstrate the generality of the proposed method and the possibility

8 to take into account any imperfections of the machine, the harmonics of the electromotive force

9 will be considered in the following calculations. These harmonics are also taken into account 10 when determining the reference behavior, namely, when the machine is fed by sinusoidal 11 currents.

\subsection{Reference classic modes}

13 The motor back-electromotive force is a periodic function of electric angle and is not necessarily

14 sinusoidal. For each phase, this voltage $e_{k}$ (with $k=a$ to $c$ corresponding respectively to $k_{1}=0$

15 to 2) can be described by:

$$
\begin{aligned}
e_{k}\left(\Omega, \theta_{e}\right)= & \frac{\Omega}{\Omega_{0}} E\left(\Omega_{0}\right) \sqrt{2} \\
& \cdot\left\{\sin \left(\theta_{e}-k_{1} \frac{2 \pi}{3}\right)+\sum_{n=2}^{\infty} a_{n} \cdot \sin \left(n \theta_{e}-\phi_{n}-k_{1} n \frac{2 \pi}{3}\right)\right\}
\end{aligned}
$$


Accepted article for publication in a future issue of ELSEVIER Electric Power Systems Research - Citation information: 10.1016/j.epsr.2016.09.014.

1 The Lagrange method based on the calculus of variations requires to define a Lagrange function

2 where $\Omega$ is the motor shaft angular rotor speed and $\Omega_{0}$ its rated value.

3 Experimental back-electromotive forces of the test bench permanent magnet synchronous 4 machine is given in Fig. 4. Indeed, in this figure, back-electromotive forces are actually not 5 purely sinusoidal.

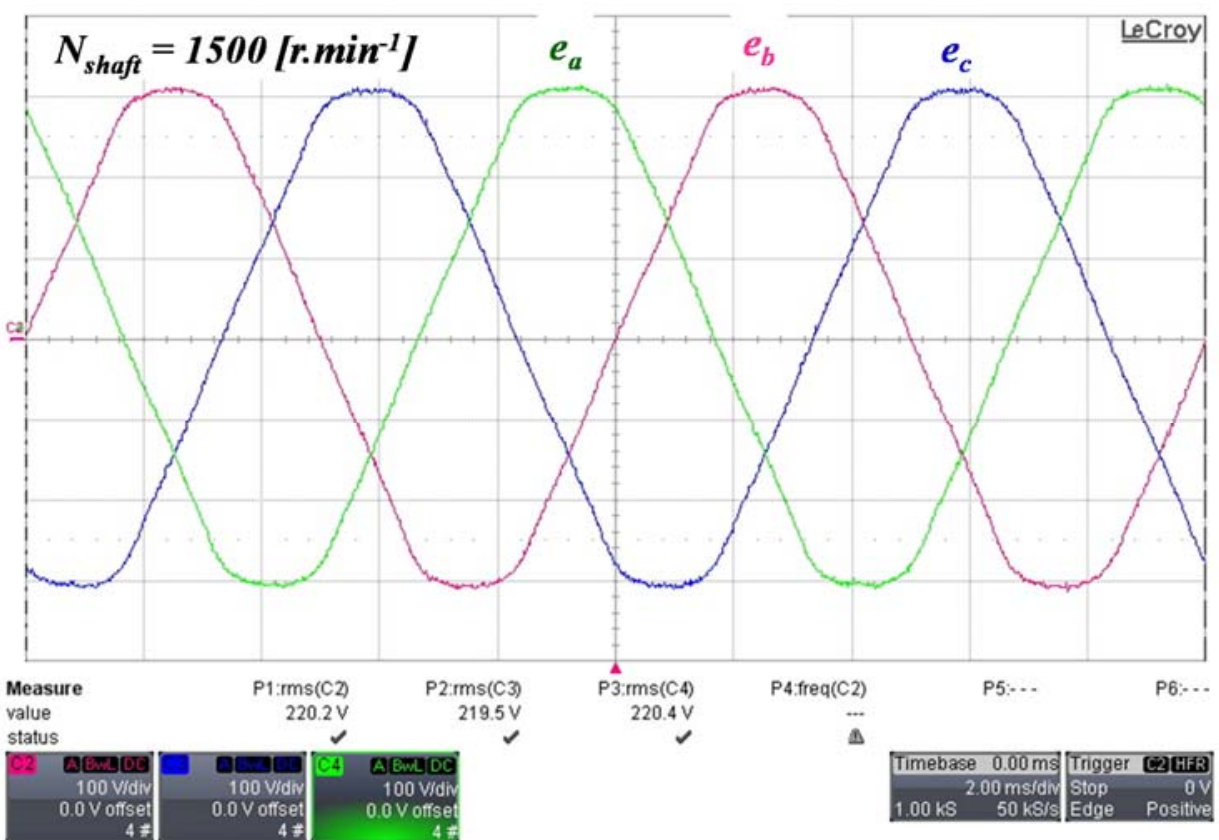

Fig. 4: 3 back electromotive forces at constant speed (1500 r.min $\left.{ }^{-1}\right)$.

8 In the basic case of sinusoidal currents, the average converted power is only driven by the back-

9 electromotive force's fundamental component. Moreover if a null zero sequence condition is

10 added for the current calculation, a given torque $T_{e m}$ leads to the following phase current:

$$
i_{k}\left(\theta_{e}\right)=I_{m a g} \cdot \sin \left(\theta_{e}-k \frac{2 \pi}{3}\right)
$$

11 Where $I_{m a g}=\left(\mathrm{T}_{e m} \Omega_{0} /\left(3 E\left(\Omega_{0}\right)\right)\right)$

12 This classic mode is used as a benchmark for the other three modes. 
Accepted article for publication in a future issue of ELSEVIER Electric Power Systems Research - Citation information: 10.1016/j.epsr.2016.09.014.

2 This mode will be associated with small power demand, and hence, aims at condensing electric

3 power on a single phase alternately. The current in the single phase used is minimal if the current

4 is injected into the phase when the absolute value of the back electromotive force is the highest.

5 Therefore this implies that one electric revolution of the machine is regularly divided into six

6 angular sectors (Fig. 5). The optimal waveform can thus be computed on a given sector, and

7 currents in the other sectors can be derived from this one.

8 Studying the first sector for example $\left(\theta_{e} \in[(\pi / 2)-(\pi / 6) ;(\pi / 2)+(\pi / 6)]\right)$ the optimization 9 is written as:

$$
\begin{gathered}
P_{e m}\left(\theta_{e}\right)=e_{a}\left(\theta_{e}\right) i_{a}\left(\theta_{e}\right) \\
\min \left(i_{a, R M S}\right)=\min \left(\int_{\theta_{i}=\pi / 3}^{\theta_{f}=2 \pi / 3}\left(i_{a}(\theta)\right)^{2} \cdot d \theta\right)
\end{gathered}
$$

10 Obviously, the solution is the unique solution of (13). Generalizing this result, phase $\mathrm{k}$ current $i_{k}$

11 is given by:

$$
i_{k}\left(\theta_{e}\right)=T_{e m} \Omega / e_{k}\left(\theta_{e}\right)
$$

12 Fig. 6 illustrates for $a$-phase the first mode current waveform in comparison with the classic

13 mode one. Obviously, each phase reference current shows abrupt variations at the beginning and

14 at the end of the phase conduction. This pattern inherently limits the first mode to low speed.

15 Indeed, as the current is switched on while the related back-emf is high, the current rising slope is

16 all the more limited than the rotor angular speed his high. Conversely, at the end of the phase

17 conduction sector, the current falling slope is increased by the electromotive force and therefore,

18 it increases with the machine rotation speed. 
Accepted article for publication in a future issue of ELSEVIER Electric Power Systems Research - Citation information: 10.1016/j.epsr.2016.09.014.

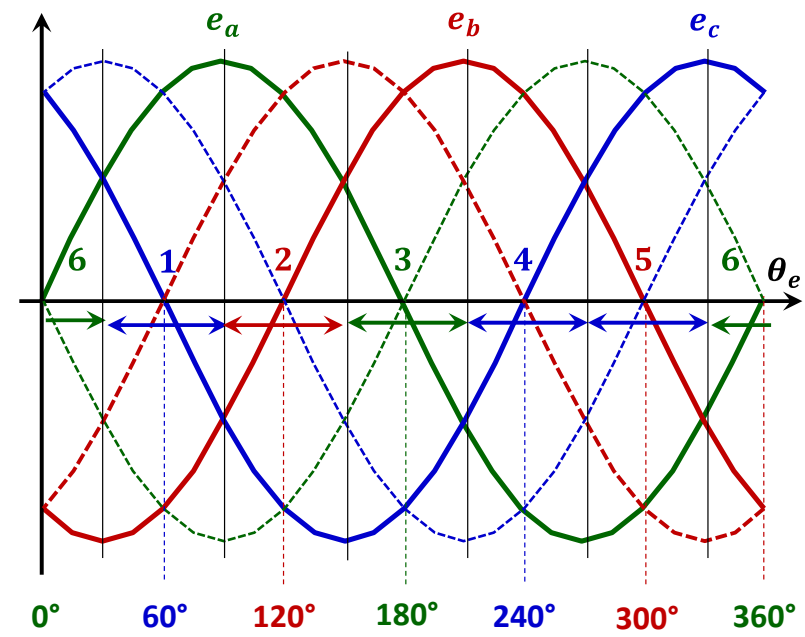

Fig. 5: 6 sectors related to first mode.

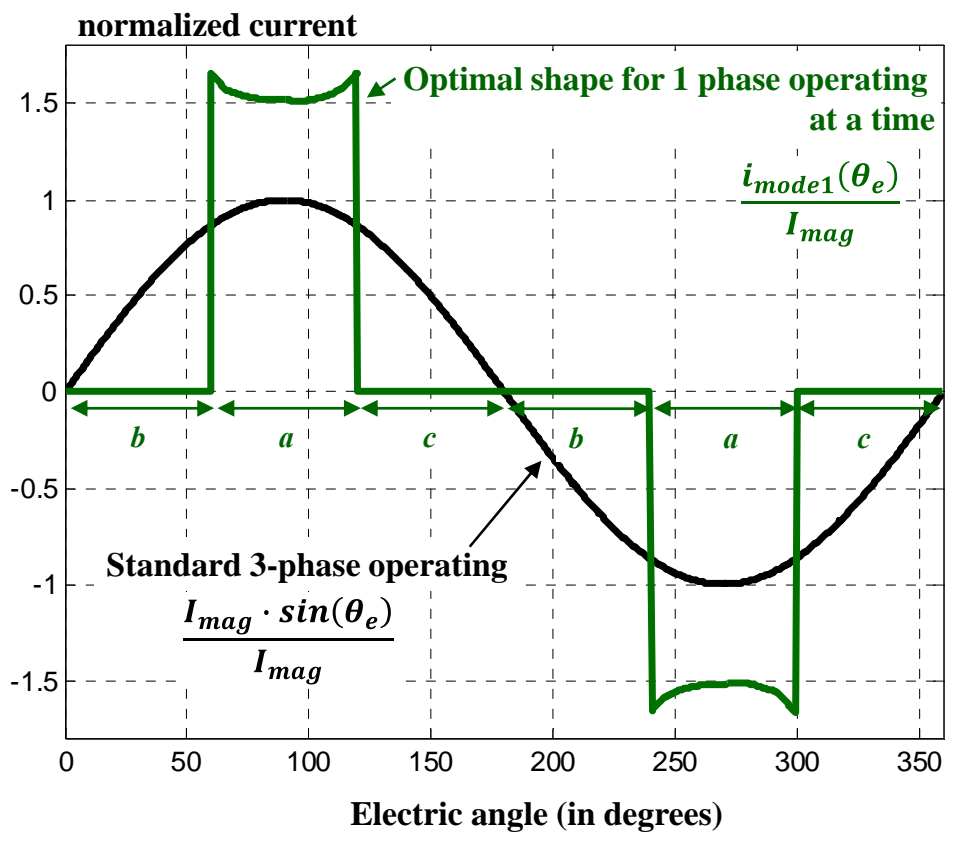

Fig. 6: First mode optimal current waveform compared to the classic one.

\subsection{Mode 2: 1 phase inhibited alternately}

6 As a consequence, for higher load, it is suitable to use two phases at the same time instead of one.

7 Hence, the new strategy involves alternately selecting two phases and thus turning-off one phase 8 cyclically. The losses minimization leads to choose the phase having the lowest back 
Accepted article for publication in a future issue of ELSEVIER Electric Power Systems Research - Citation information: 10.1016/j.epsr.2016.09.014.

1 electromotive force absolute value. Hence, for each specific position, the electric power is

2 concentrated on the two phases with the highest electromagnetic potential. This also leads the

3 division of an electric revolution into six sectors of the same size $(\pi / 3)$. They are $\pi / 6$ out of

4 phase with the six first mode sectors. Considering the first sector $\left(\theta_{e} \in[\pi / 6 ; \pi / 2]\right)$, the

5 optimization problem is expressed as follows:

$$
\begin{gathered}
P_{e m}\left(\theta_{e}\right)=e_{a}\left(\theta_{e}\right) i_{a}\left(\theta_{e}\right)+e_{b}\left(\theta_{e}\right) i_{b}\left(\theta_{e}\right) \\
\min \left(\int_{\theta_{i}=\pi / 6}^{\theta_{f}=\pi / 2}\left\{\left(i_{a}(\theta)\right)^{2}+\left(i_{b}(\theta)\right)^{2}\right\} \cdot d \theta\right)
\end{gathered}
$$

6 This involves solving the following set of equations:

$$
\left\{\begin{array}{c}
2 . i_{a}+\lambda \cdot e_{a}=0 \\
2 \cdot i_{b}+\lambda \cdot e_{b}=0 \\
e_{a} i_{a}+e_{b} i_{b}-P_{e m}=0
\end{array}\right.
$$

7 The solution is defined as follows:

$$
i_{k}\left(\theta_{e}\right)=T_{e m} \Omega e_{k}\left(\theta_{e}\right) /\left(e_{a}^{2}\left(\theta_{e}\right)+e_{b}^{2}\left(\theta_{e}\right)\right) \quad k=\{a ; b\}
$$

8 Despite appearances and for a given electromagnetic torque, the current shape is independent of

9 the rotation speed, since the back electromotive force is proportional to speed. Fig. 7 shows the

10 current of a-phase as well as the shape of the conventional mode reference current expressed in

11 (12). As in Mode 1, each phase reference current exhibits four abrupt variations per electric

12 period. In contrast, the magnitude of the current step is lower, namely 2.91 times smaller.

13 Moreover, the second mode has degree of freedom meaning that it can take into account extra

14 constraints, such as current slope limitations. This latter issue is discussed in section IV dealing

15 with the proposed modes' implementation. This specific feature makes it possible to use this

16 mode with limited slew rate at higher speed. 
Accepted article for publication in a future issue of ELSEVIER Electric Power Systems Research - Citation information: 10.1016/j.epsr.2016.09.014.

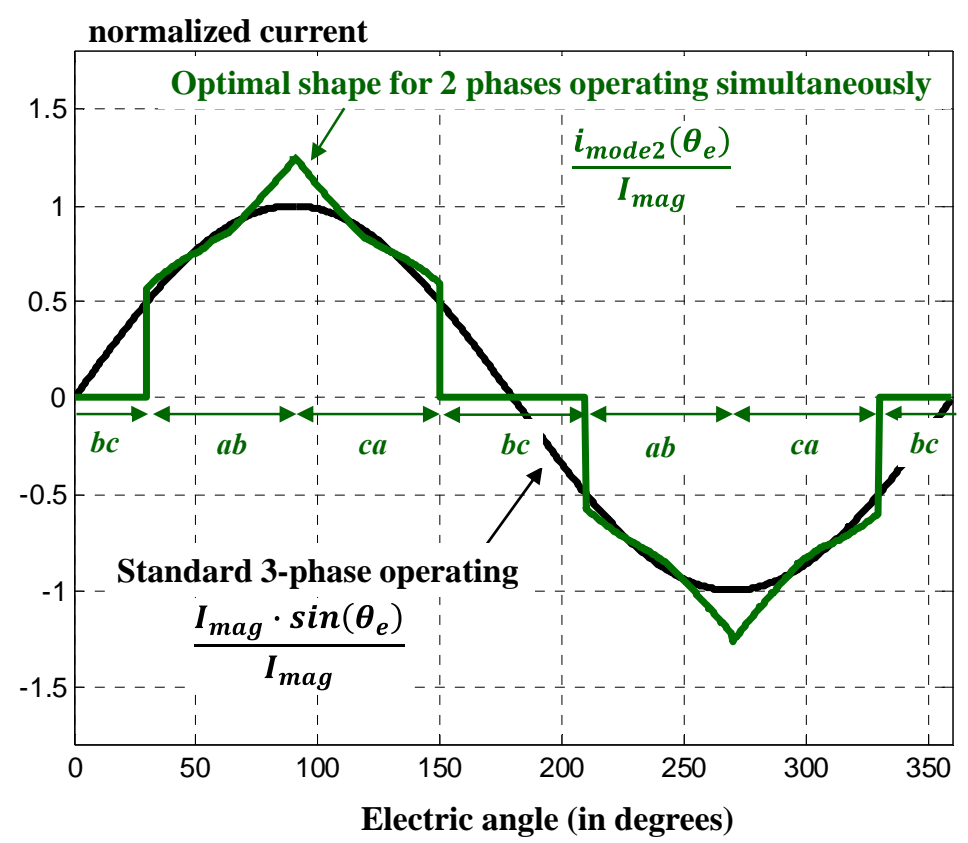

Fig. 7: Second mode optimal current waveform compared to the classic one.

3.4.Mode 3: phases functioning continuously

In the case of a high load operation, it is necessary to use all phases simultaneously. It is rare for back electromotive forces to be purely sinusoidal, hence the optimal currents should also contain some harmonics. Solving (10) provides precisely the optimal waveform solution. In this mode, optimal 3-phase currents are defined as:

$$
i_{k}\left(\theta_{e}\right)=T_{e m} \Omega e_{k}\left(\theta_{e}\right) /\left(e_{a}^{2}\left(\theta_{e}\right)+e_{b}^{2}\left(\theta_{e}\right)+e_{c}^{2}\left(\theta_{e}\right)\right)
$$

8 Fig. 8 illustrates the third mode optimal current shape. Note that, with the PMSM under test, it is

9 very close to the classic one. If the zero torque ripple constraint expressed by (3) yields to infinite

10 solutions of current waveforms, on the basis of the minimum RMS value (4) it must be concluded

11 that the optimal waveform is not the classic sinusoidal one. Because of the presence of back-emf

12 harmonic components, it should also be noted that the classic mode does not strictly satisfy the

13 zero torque ripple constraint. 
Accepted article for publication in a future issue of ELSEVIER Electric Power Systems Research - Citation information: 10.1016/j.epsr.2016.09.014.

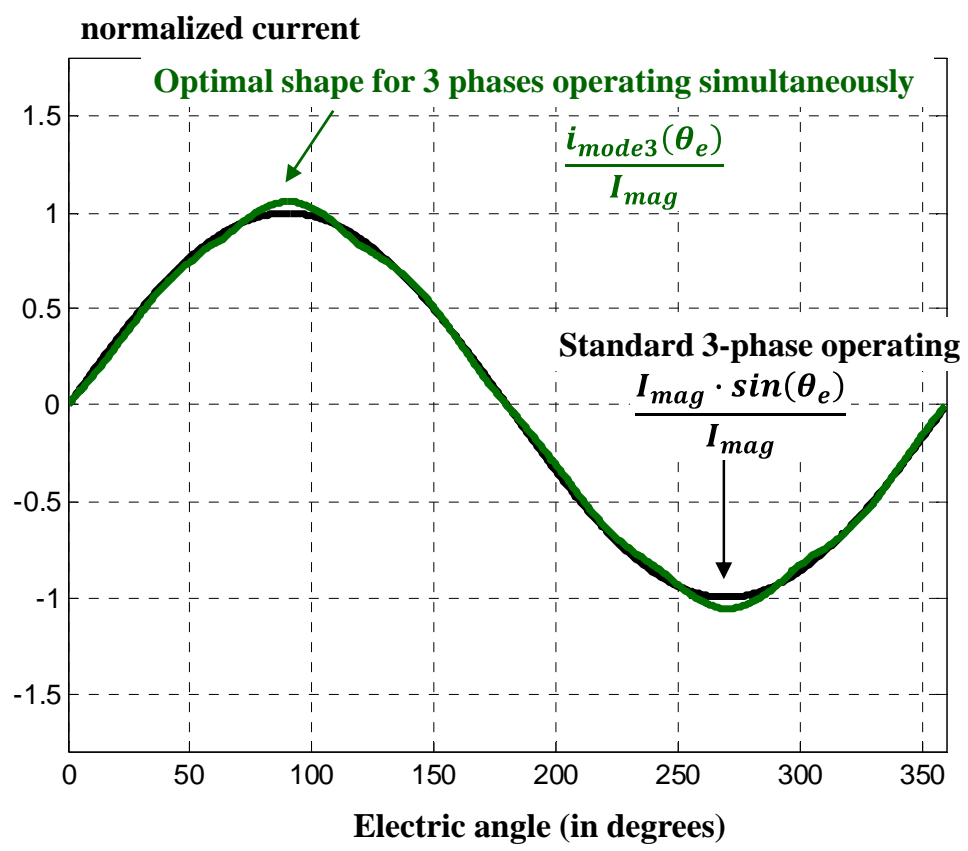

Fig. 8: Third mode optimal current waveform compared to the classic one.

4 The open-end winding drive architecture enables the drive of each motor phase independently.

5 Thus, it not only allows post-default operation but it also permits to optimize drive current

6 waveform. The present section shows how to conveniently exploit the mentioned degree of

7 freedom in normal mode with the purpose of minimizing losses. The previous section described

8 three different modes of operation, and for each one, gave the best analytical current shape. The

9 range of application of each mode must now be defined. This can be done by using key indicators

10 associated to each mode. These indicators are no-load losses, amplitude and RMS value of the

11 phase currents. The values of these indicators calculated relatively to those of the conventional 12 operation mode for the same electromagnetic torque are given in Tab. 1.

13 1. Clearly, Mode 1 is more suited to low-load. In this mode, no-load losses are three times 14 lower than for conventional mode. However, the very large magnitude and RMS value of 
Accepted article for publication in a future issue of ELSEVIER Electric Power Systems Research - Citation information: 10.1016/j.epsr.2016.09.014.

the phase currents penalize this mode of operation by greatly increasing the Joule losses at high load. This is therefore not optimal to achieve high torque values with Mode 1.

2. It is particularly interesting to note that the second mode RMS current is very similar to that of the classic mode. This means that this mode will be the best choice for a wide range of electromagnetic torques as no-load losses are, in this case, only two-thirds of the classic mode.

3. Last but not least, Mode 3, corresponding to a conventional mode of operation but with optimized current waveforms, does not lead to significant differences in the RMS current. This mode does not provide a significant gain in performance and is therefore not of great interest.

11 After this brief review, the following section intends to give a proof of concept related to these 12 results. 
Accepted article for publication in a future issue of ELSEVIER Electric Power Systems Research - Citation information: 10.1016/j.epsr.2016.09.014.

Tab.1: Key indicators for each proposed modes

\begin{tabular}{cccc}
\hline \hline Indicator & Mode 1 & Mode 2 & Mode 3 \\
\hline$\frac{I_{\text {mode,mag }}}{I_{\text {sinus }, \text { mag }}}$ & 1.662 & 1.263 & 1.059 \\
$\frac{I_{\text {mode }, R M S}}{I_{\text {sinus }, R M S}}$ & 1.268 & 1.031 & 1.002 \\
$\frac{\text { Fatal losses }}{k_{0}}$ & $\frac{1}{3}$ & $\frac{2}{3}$ & 1
\end{tabular}

$3 I_{\text {sinus,RMS }}$ and $I_{\text {sinus,mag }}$ and $\overline{\overline{k_{0}} \text { are the relative magnitude current, effective current }}$ and no-load 4 losses respectively.

Tab. 1: Key indicators for each proposed mode.

\section{4. InNovative Approach Proof Of Concept}

7 An experimental test bench has been developed to validate the suggested strategy. The goal is

8 twofold. First, it has to be shown experimentally that a simple current control scheme can track

9 the various proposed current references. Secondly, trials should demonstrate that the innovative

10 proposed strategy improves electromechanical conversion efficiency.

11 4.1. Experimental Test Bench

12 The experimental setup (Fig. 9) is built around the following devices:

13 - A permanent magnet synchronous machine (PMSM) designed by LEROY SOMER. Its 14 key features are summarized in Tab 2. The motor has concentrated windings (stator) and 15 interior-magnets (rotor) as shown in Fig. 10. It can reach high speed value 
Accepted article for publication in a future issue of ELSEVIER Electric Power Systems Research - Citation information: 10.1016/j.epsr.2016.09.014. $\left(\mathrm{N}_{\text {rated }}=3500 \mathrm{r} \cdot \mathrm{min}^{-1}\right)$ in case it is fed with high voltage (in the order of $1 \mathrm{kV}$ ). To achieve this, a boost power converter ensuring the connection of the battery with the inverter permits to meet DC bus high voltage requirement [31]. This additional degree of freedom is not considered in this study. The present work only focuses on the optimization of the inverter degree of freedom. Consequently, the battery is directly connected to the inverter DC bus and a $300 \mathrm{~V}$ level leads to a base speed of $1230 \mathrm{r} . \mathrm{min}^{-1}$, which represents $0.35 \mathrm{pu}$;

- A power inverter (ARCEL) configured in 3 full H-bridges using 6 IGBT modules (1200V / $150 \mathrm{~A} @ 25^{\circ} \mathrm{C}$ ). Each H-bridge output separately supplies a specific motor phase; encoder (IVO Industries) on the motor shaft;

- An AGILENT voltage source set to $300 \mathrm{~V}$ with an $11 \mathrm{~A}$ rated current. It powers the inverter DC bus;

- A 5.5-kW induction machine (IM) is mechanically coupled to the PMSM under test and is controlled using OMRON 2G2 drive in the speed control mode. Thus it provides loading onto the PMSM;

- An active load (AMREL) connected to the OMRON drive dissipates the power supplied by the IM;

- A host PC connected to a DSPACE real-time control system mainly composed of a DS1006 processor board, a DS3001 incremental encoder interface board and a DS5203 FPGA board. This system enables to achieve analogue-to-digital conversions, the PWM vector control and current controllers. Programs to be run on this system are written by the user in a Matlab-Simulink language. The host PC also provides real time facilities to monitor the processes through Control-desk software. 
Accepted article for publication in a future issue of ELSEVIER Electric Power Systems Research - Citation information: 10.1016/j.epsr.2016.09.014.

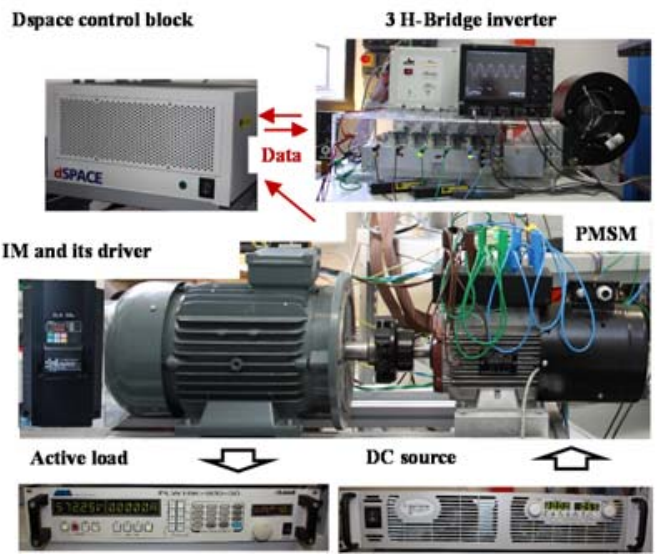

Fig. 9 : Experimental setup view.

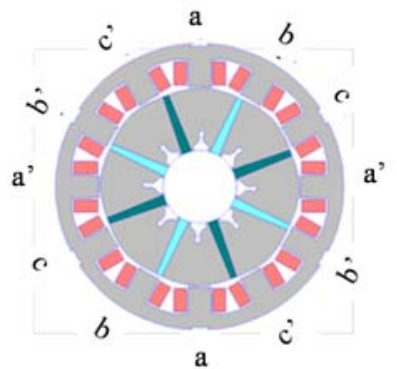

Fig. 10 : PMSM structure.

5 
Accepted article for publication in a future issue of ELSEVIER Electric Power Systems Research - Citation information: 10.1016/j.epsr.2016.09.014.

TAB.2: PMSM CHARACTERISTICS

\begin{tabular}{|c|c|c|}
\hline Symbol & Parameter & Value \\
\hline $\mathrm{R}$ & Stator phase resistance & $1.72 \Omega$ \\
\hline $\mathrm{Ld}_{\mathrm{d}}$ & $\mathrm{d}$-axis self-inductance & $14 \mathrm{mH}$ \\
\hline $\mathrm{Lq}_{\mathrm{q}}$ & q-axis self-inductance & $12.5 \mathrm{mH}$ \\
\hline $\mathrm{L}_{0}$ & 0 -axis self-inductance & $1.3 \mathrm{mH}$ \\
\hline $\mathrm{p}$ & number of motor pole pairs & 4 \\
\hline$\Psi_{M}$ & amplitude of the induced flux & $0.494 \mathrm{~Wb}$ \\
\hline $\mathrm{K}_{\mathrm{SM}, 1}$ & $1^{\text {st }}$ harmonic back-e.m.f. constant & 1.417 V.s \\
\hline $\mathrm{K}_{\mathrm{SM}, 3}$ & $3^{\text {rd }}$ harmonic back-e.m.f. constant & 0.0354 V.s \\
\hline $\mathrm{K}_{\mathrm{SM}, 5}$ & $5^{\text {st }}$ harmonic back-e.m.f. constant & 0.0354 V.s \\
\hline $\mathrm{T}_{\text {rated }}$ & Rated torque & $42.5 \mathrm{Nm}$ \\
\hline $\mathrm{N}_{\text {rated }}$ & Rated speed & 3500 r.min ${ }^{-1}$ \\
\hline $\mathrm{V}_{\text {rated }}$ & Rated voltage & $970 \mathrm{~V}$ \\
\hline Irated & Rated current & $10 \mathrm{~A}$ \\
\hline
\end{tabular}


Accepted article for publication in a future issue of ELSEVIER Electric Power Systems Research - Citation information: 10.1016/j.epsr.2016.09.014.

1 A critical point of the proposed method is the capability of the current regulators to track the

2 suggested reference currents. Therefore the following subsection describes this issue.

\subsection{Implemented current regulators for each mode}

4 Fig. 11 depicts both power architecture and its related control structure. The structure and the parameters tuning of the current controllers are based on the motor's dynamics. However, the current behavior depends on the mode used. Therefore the description of the current regulators is outlined in the 3 modes considered.

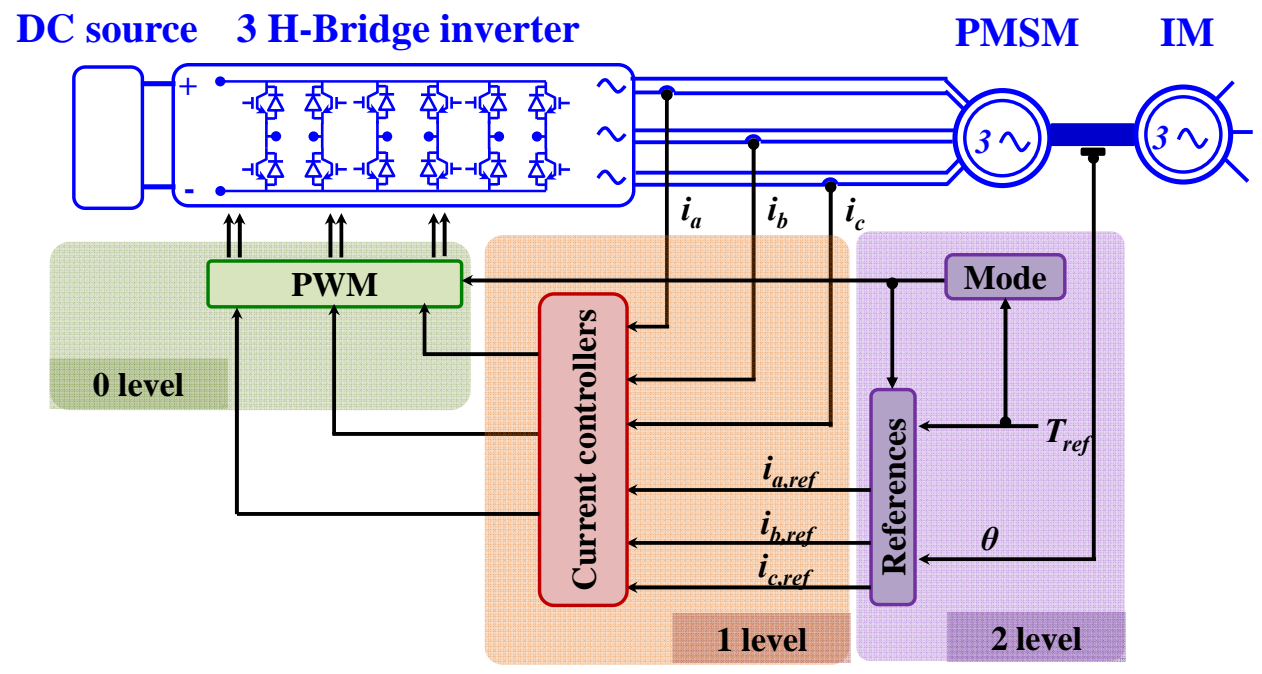

8

11 In the first mode, the motor is a single input (the unique phase voltage $v_{k}$, with $k=a, b$, or $c$ )

12 single output (the related phase current $i_{k}$ ) system subject to a measured disturbance (the related

13 electromotive force emf $e_{k}$ ). In a $60^{\circ}$ angle sector, the current dynamic can be described by the

14 following classical differential equation:

$$
v_{k}=R i_{k}+L \frac{d i_{k}}{d t}+e_{k}
$$

15 with $\mathrm{L}$ the phase self-inductance, $\mathrm{R}$ the phase resistance. 
Accepted article for publication in a future issue of ELSEVIER Electric Power Systems Research - Citation information: 10.1016/j.epsr.2016.09.014.

1 To tackle the current tracking issue, the combination of the back-emf compensation and an

2 integral and proportional controller (IP), as defined in [47], is adopted. As the phase voltage is

3 supplied by a power inverter, the IP gains are tuned to meet the conditions for validity of the

4 above average model. This leads to adopt a closed-loop bandwidth twenty times smaller than the

5 switching frequency, namely $f_{c l}=1 \mathrm{kHz}$.

6 In the sectors where the phase has to be inhibited, all the related IGBT switches are off, while the

7 integral value is imposed to zero permitting a good starting transient behavior when the phase is

8 switch on again. When the phase is switched off, the related diodes ensured the continuity of

9 current and also permits the most efficient and rapid extinction of the current in the phase.

10 Figure 12 summarizes the implementation of the first mode current controller.

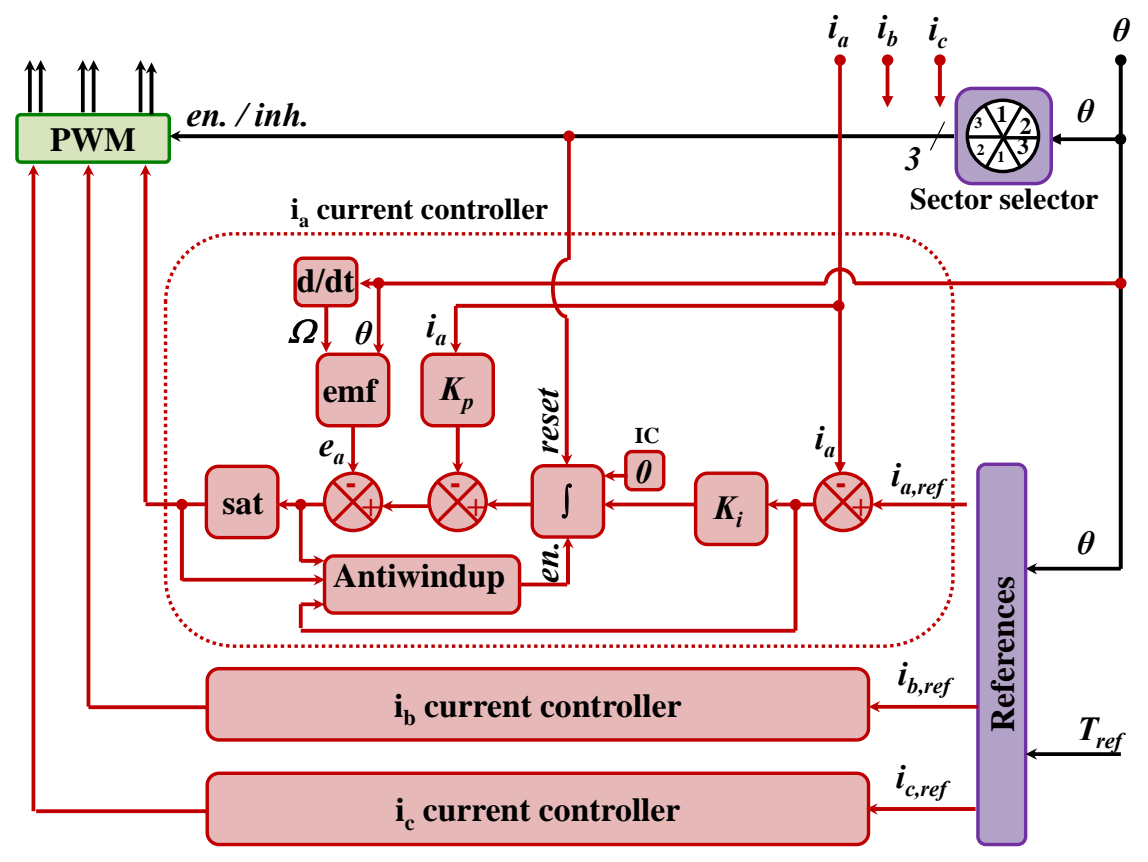

Fig. 12 : Current controller of the first mode. 
Accepted article for publication in a future issue of ELSEVIER Electric Power Systems Research - Citation information: 10.1016/j.epsr.2016.09.014.

\subsubsection{Second mode current controller}

2 In the second mode, the motor is a multivariable system with two inputs and two outputs, the two

3 conducting phase voltages and currents respectively. In a $60^{\circ}$ angle sector, the current dynamic is

4 governed by the following differential equation:

$$
\left[\begin{array}{l}
v_{k 1} \\
v_{k 2}
\end{array}\right]=R\left[\begin{array}{l}
i_{k 1} \\
i_{k 2}
\end{array}\right]+\left[\begin{array}{cc}
L & M \\
M & L
\end{array}\right] \frac{d}{d t}\left[\begin{array}{l}
i_{k 1} \\
i_{k 2}
\end{array}\right]+\left[\begin{array}{l}
e_{k 1} \\
e_{k 2}
\end{array}\right]
$$

5 with $\mathrm{M}$ the mutual inductance between two conducting phases, and $\left[k_{1}, k_{2}\right]$ being one of the

6 following couple: $[a, b],[c, a],[b, c]$.

7 The proposed control strategy is similarly based on IP regulator combined with emf

8 compensation. To do so, the linear dynamic model has to be decoupled using a specific

9 transform. Based on linear algebra, and more specifically on matrix diagonalization and eigen

10 decomposition, the following matrix transform is suggested:

$$
\left[\begin{array}{l}
x_{\Gamma} \\
x_{\Delta}
\end{array}\right]=T\left[\begin{array}{l}
x_{k 1} \\
x_{k 2}
\end{array}\right]=\frac{1}{\sqrt{2}}\left[\begin{array}{cc}
1 & 1 \\
-1 & 1
\end{array}\right]\left[\begin{array}{l}
x_{k 1} \\
x_{k 2}
\end{array}\right]
$$

11 It leads to the decoupled model in the new frame $\left[x_{\Gamma}, x_{\Delta}\right]^{t}$ :

$$
\left[\begin{array}{l}
v_{\Gamma} \\
v_{\Delta}
\end{array}\right]=R\left[\begin{array}{l}
i_{\Gamma} \\
i_{\Delta}
\end{array}\right]+\left[\begin{array}{cc}
L-M & 0 \\
0 & L+M
\end{array}\right] \frac{d}{d t}\left[\begin{array}{l}
i_{\Gamma} \\
i_{\Delta}
\end{array}\right]+\left[\begin{array}{l}
e_{\Gamma} \\
e_{\Delta}
\end{array}\right]
$$

12 Using these virtual values, the current control design is fully similar to the first mode one.

13 Figure 13 shows an overview of the second mode current controller. 
Accepted article for publication in a future issue of ELSEVIER Electric Power Systems Research - Citation information: 10.1016/j.epsr.2016.09.014.

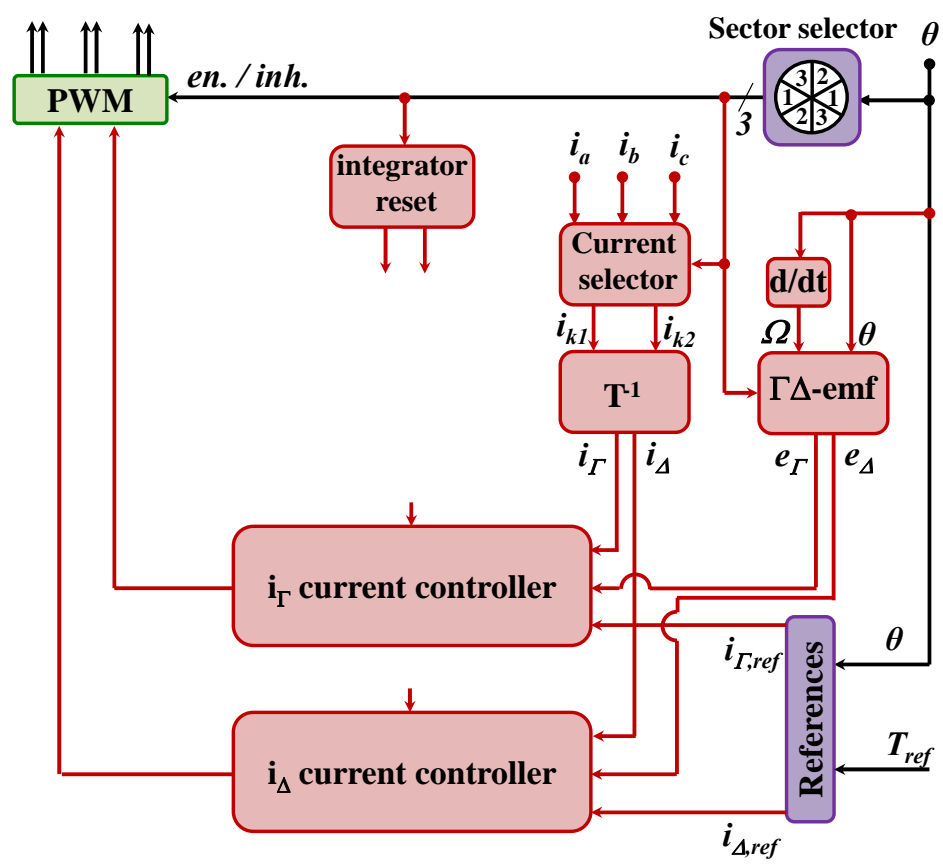

Fig. 13 : Current controller of the second mode.

\subsubsection{Third mode current controller}

4 In the third mode, the motor is a multivariable system with three inputs and three outputs

described by the following 3-equations system:

$$
\left[\begin{array}{l}
v_{a} \\
v_{b} \\
v_{c}
\end{array}\right]=R\left[\begin{array}{l}
i_{a} \\
i_{b} \\
i_{c}
\end{array}\right]+\left[\begin{array}{ccc}
L & M & M \\
M & L & M \\
M & M & L
\end{array}\right] \frac{d}{d t}\left[\begin{array}{l}
i_{a} \\
i_{b} \\
i_{c}
\end{array}\right]+\left[\begin{array}{l}
e_{a} \\
e_{b} \\
e_{c}
\end{array}\right]
$$

6 This current control issue has already been studied in many research works using classic Park

7 transform [42]. The key feature of this power architecture is that the zero sequence mode has also

8 to be controlled, which is challenging because the zero sequence inductance $\mathrm{L}_{0}$ is small leading to

9 fast natural dynamic and high current ripples due to inverter switching [42,43,47]. Figure 14

10 depicts the third mode current controller. 
Accepted article for publication in a future issue of ELSEVIER Electric Power Systems Research - Citation information: 10.1016/j.epsr.2016.09.014.

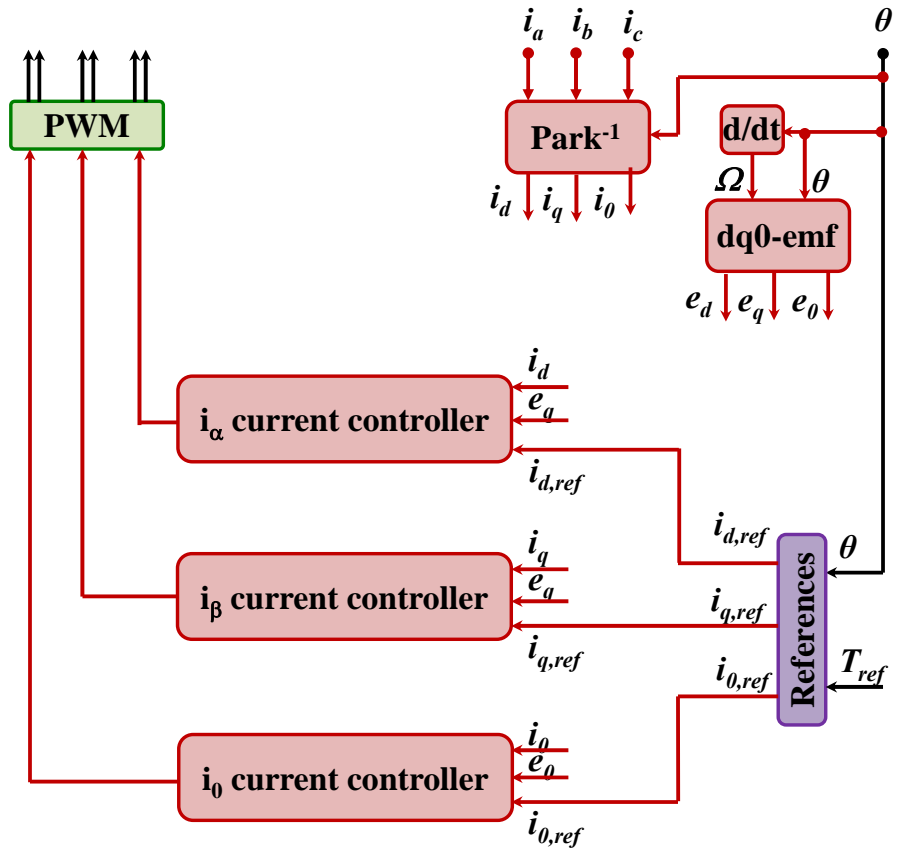

Fig. 14 : Current controller of the third mode.

4 Several tests are conducted and analyzed using this experimental setup and the current regulators explained above.

\subsection{Self-control modes behavior}

7 The first goal of the experiments is to test the ability of the implemented control scheme to track

8 the current reference efficiently in the three suggested modes. Trials presented in this section are

9 performed under the same rotation speed, i.e. $N_{1}=150 \mathrm{r} \mathrm{min}^{-1}$ and $N_{2}=600 \mathrm{r} \mathrm{min}^{-1}$. At the

10 first speed $\left(N_{1}\right)$, Fig. 15 shows the 3-phase currents of each mode, which produce the same

11 average electromagnetic torque (i.e. $T_{e m}=0.706 \mathrm{pu}$ ). It also shows the instantaneous motor

12 torque. The oscilloscope is triggered when the electric angle reaches $\pi$ value. In each situation, it

13 is clear that the real-time control implementation enables to track precisely the related reference. 
Accepted article for publication in a future issue of ELSEVIER Electric Power Systems Research - Citation information: 10.1016/j.epsr.2016.09.014.

1 To produce the same torque, peak and RMS currents are decreasing from first to third mode.

2 These results are consistent with the theoretical study (see Tab. 3).

3 However, it may also be noticed that in Modes 1 and 2, the current shape presents slight

4 differences during a small duration at the switching time between two different sectors:

5 First, switching from a sector to another requires steep current edges, which are difficult to track

6 with a limited DC bus voltage. In the first two modes, this problem results in the small switching

7 time required to reach the current reference when the current starts from zero. As the energy

8 optimization has led to select a phase conduction regarding its back-emf, it is important to notice

9 that the back-emf value contributes to improve the current decay. Conversely, the emf value

10 reduces the ability of the inverter to enforce a high current rising slope. It is for this latter reason

11 that the first two modes are intrinsically limited to low speed. Indeed, the back-emf magnitude

12 increases with speed linearly. As a consequence, the real currents show an asymmetrical

13 waveform different to the symmetrical references. This mismatch increases with motor speed.

14 Secondly, magnetic couplings inside the motor may lead briefly to unwanted current behavior. In

15 Mode 1, this is noticeable during the current impulse occurring in the inhibited phase while the

16 current in the two other phases switches. Regarding the second mode, this is also visible in the

17 slight overcurrent occurring in the turn-on phase during a sector switch.

18 The discrepancy between current references and real currents explains the torque ripple which

19 occurs at each sector switching. This phenomenon becomes more pronounced as speed increases

20 as illustrated by Fig. 16. With regard to Mode 1, as the current waveform solution is unique, it

21 does not make it possible to consider suboptimal solutions at high speed. Consequently Mode 1 is

22 limited to the low speed range. Conversely, Mode 2 presents a degree of freedom which was first 
Accepted article for publication in a future issue of ELSEVIER Electric Power Systems Research - Citation information: 10.1016/j.epsr.2016.09.014.

1 used for minimizing the current RMS value by focusing solely on achieving a constant torque.

2 However, the chosen constraint can be modified leading to a different solution.

3 That is the reason why the next subsection suggests an enhancement of Mode 2 at high speed

4 while subsection 4.5 analyses losses measurement with the aim of assessing the real profits of 5 using such an approach, despite its small imperfections.

Tab.3: MEASURED CURRENT CHARACTERISTICS

\begin{tabular}{cccc}
\hline \hline Current & Mode 1 & Mode 2 & Mode 3 \\
& & & \\
\hline Magnitude & $13.5 \mathrm{~A}$ & $10.5 \mathrm{~A}$ & $8.8 \mathrm{~A}$ \\
RMS & $8.718 \mathrm{~A}$ & $7.062 \mathrm{~A}$ & $6.840 \mathrm{~A}$ \\
\hline \hline \multicolumn{4}{c}{ @ 150 r.min $^{-1}$ and 30 Nm. }
\end{tabular}


Accepted article for publication in a future issue of ELSEVIER Electric Power Systems Research - Citation information: 10.1016/j.epsr.2016.09.014.
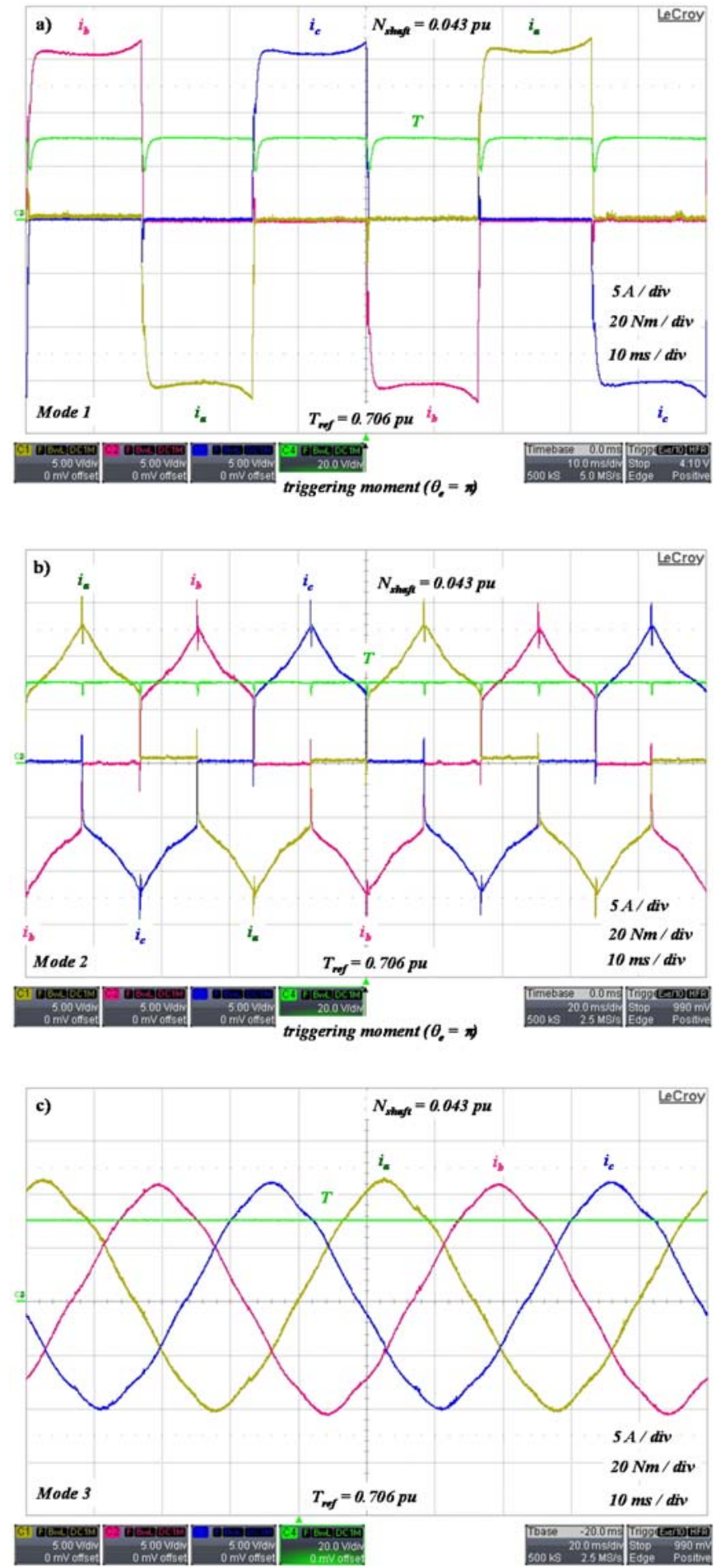

4 Fig. 15 : 3-phase current and related torque in the 3 suggested modes at $N_{1}=150 \mathrm{rmin}^{-1}$. 
Accepted article for publication in a future issue of ELSEVIER Electric Power Systems Research - Citation information: 10.1016/j.epsr.2016.09.014.
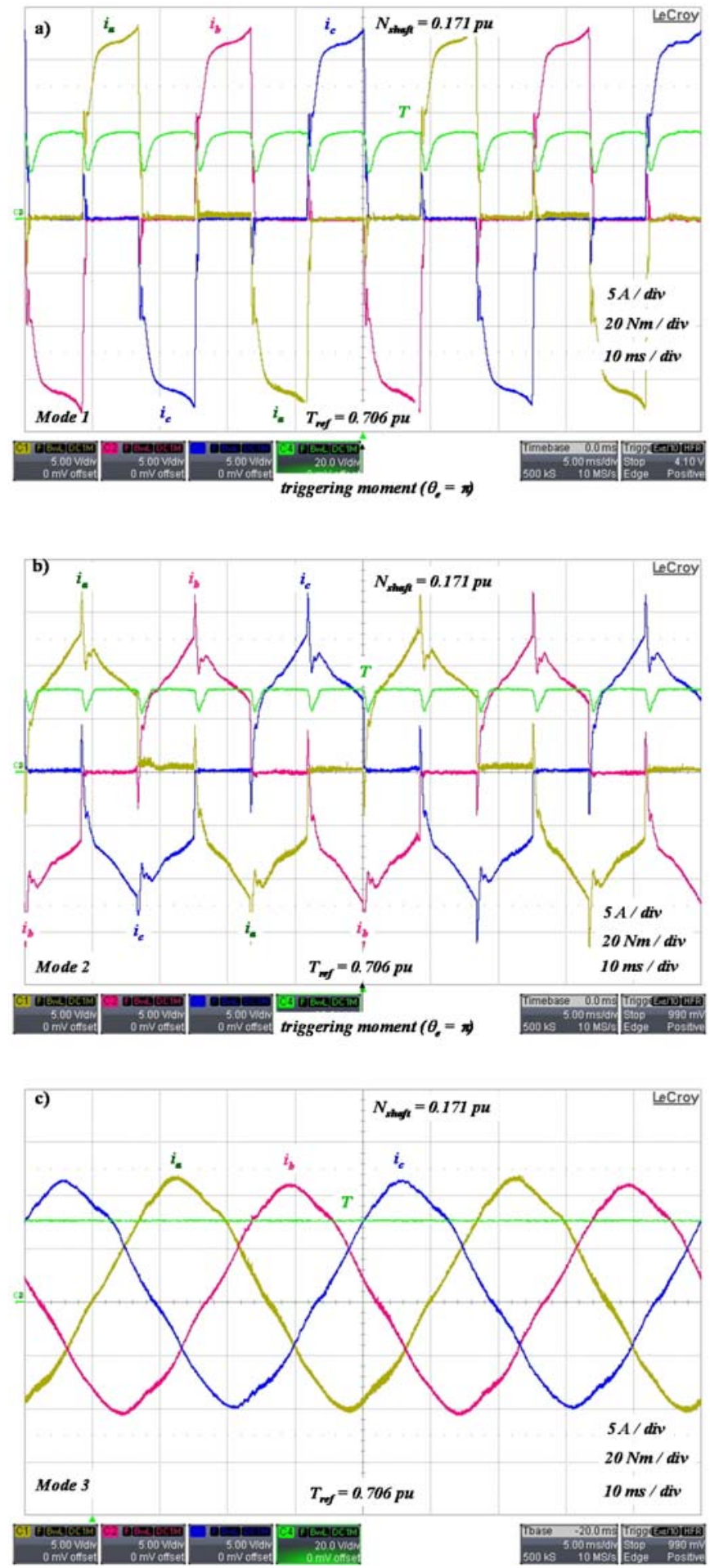

4 Fig. 16 : 3-phase current and related torque in the 3 suggested modes at $N_{2}=600 \mathrm{r} \mathrm{min}^{-1}$. 
Accepted article for publication in a future issue of ELSEVIER Electric Power Systems Research - Citation information: 10.1016/j.epsr.2016.09.014.

4.4. Mode 2 with limited slew rate (Mode 2,lsr)

2 As noted in the description of previous experiments, the starting current edge is intrinsically all

3 the more difficult to achieve than the motor speed increases. Nonetheless, using 1 phase inhibited

4 alternately strategy allows to meet the constraint of a constant instantaneous torque with unlimited possibilities. Consequently it is possible to consider extra constraints like the limited current slope due to finite DC bus voltage. Specifically, while the speed increases, the actual current waveform becomes too asymmetrical and it is better to modify the constraint in order to guarantee a real zero torque ripple. This new mode is called Mode 2,lsr for Mode 2 with limited

9 slew rate. To achieve this, it is then mandatory to start each phase conduction from a zero current 10 and to constraint the current rate in a given range around zero, while still enforcing continuous 11 constant torque. The optimization problem is now expressed as follows:

$$
\begin{gathered}
P_{e m}\left(\theta_{e}\right)=e_{a}\left(\theta_{e}\right) i_{a}\left(\theta_{e}\right)+e_{b}\left(\theta_{e}\right) i_{b}\left(\theta_{e}\right) \\
\min \left(\int_{\theta_{i}=\pi / 6}^{\theta_{f}=\pi / 2}\left\{\left(i_{a}(\theta)\right)^{2}+\left(i_{b}(\theta)\right)^{2}\right\} \cdot d \theta\right) \\
i_{a}\left(\theta_{i}=\pi / 6\right)=0 \text { and } i_{a}\left(\theta_{f}=\pi / 2\right)=-i_{b}\left(\theta_{i}=\pi / 6\right) \\
\text { Slope }_{\text {min }} \leq d i_{a}(\theta) / d \theta \leq+ \text { Slope }_{\text {max }}
\end{gathered}
$$

12 Note that setting the first initial current $i_{a}$ to zero imposes the second initial current $i_{b}$ to zero 13 using (26); this latter is obviously the final condition of the first current.

14 This optimization problem can be easily solved numerically by discretizing the electric angle $\theta$. It 15 was done for various slew rate range. In case of Slope $e_{\max }=-S l o p e_{\min }=1.5 \times I_{\max } /(\pi / 3)$, 16 Fig. 17 shows the experimental value of the motor torque and the related 3-phase currents at $N_{2}$ 17 and $T_{e m}=0.706 \mathrm{pu}$. The symmetrical current waveform and consequently the absence of torque 18 ripple are reflected in Fig. 17. It also shows that the current has three behaviors on a half 
Accepted article for publication in a future issue of ELSEVIER Electric Power Systems Research - Citation information: 10.1016/j.epsr.2016.09.014.

1 conduction sector: it is first limited in slew rate, then follows a curve similar to Mode 2

2 waveform and finally has a restricted slope. As a consequence, Mode 2, lsr is a good option for

3 increasing the speed range of the studied power partitioning strategy of motor drives.

4 To illustrate the good dynamic behavior of the suggested modes, it is chosen to show the torque

5 tracking while connecting the torque reference to a square-wave generator having a frequency of

$620 \mathrm{~Hz}$, a minimum value of $0.24 \mathrm{pu}$ and a maximum value of $0.71 \mathrm{pu}$. Fig 18 shows expected

7 behavior of currents and torque. Specifically, the torque response time is in the range of a

8 millisecond, as expected.

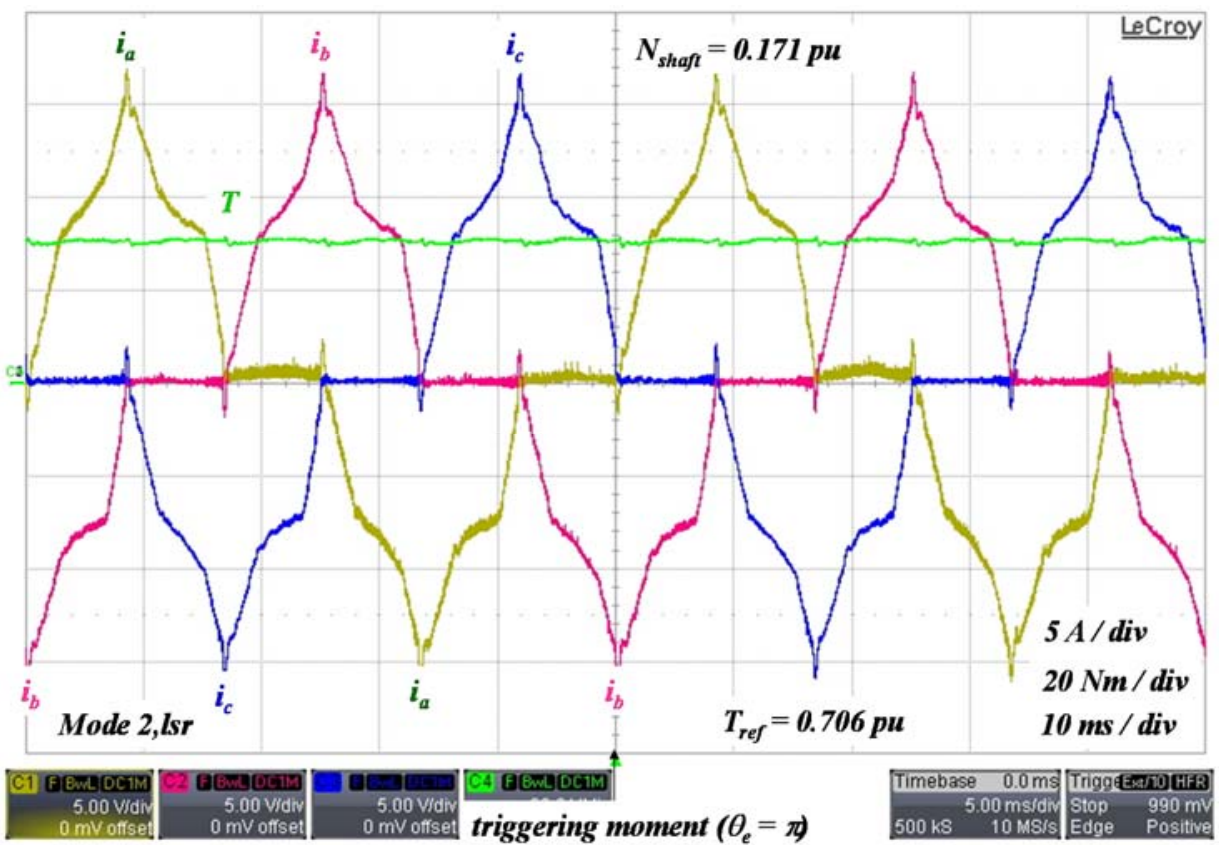

Fig. 17 : 3-phase current and related torque in Mode 2,lsr in steady state at $N_{2}=$

$600 \mathrm{rmin}^{-1}$. 
Accepted article for publication in a future issue of ELSEVIER Electric Power Systems Research - Citation information: 10.1016/j.epsr.2016.09.014.

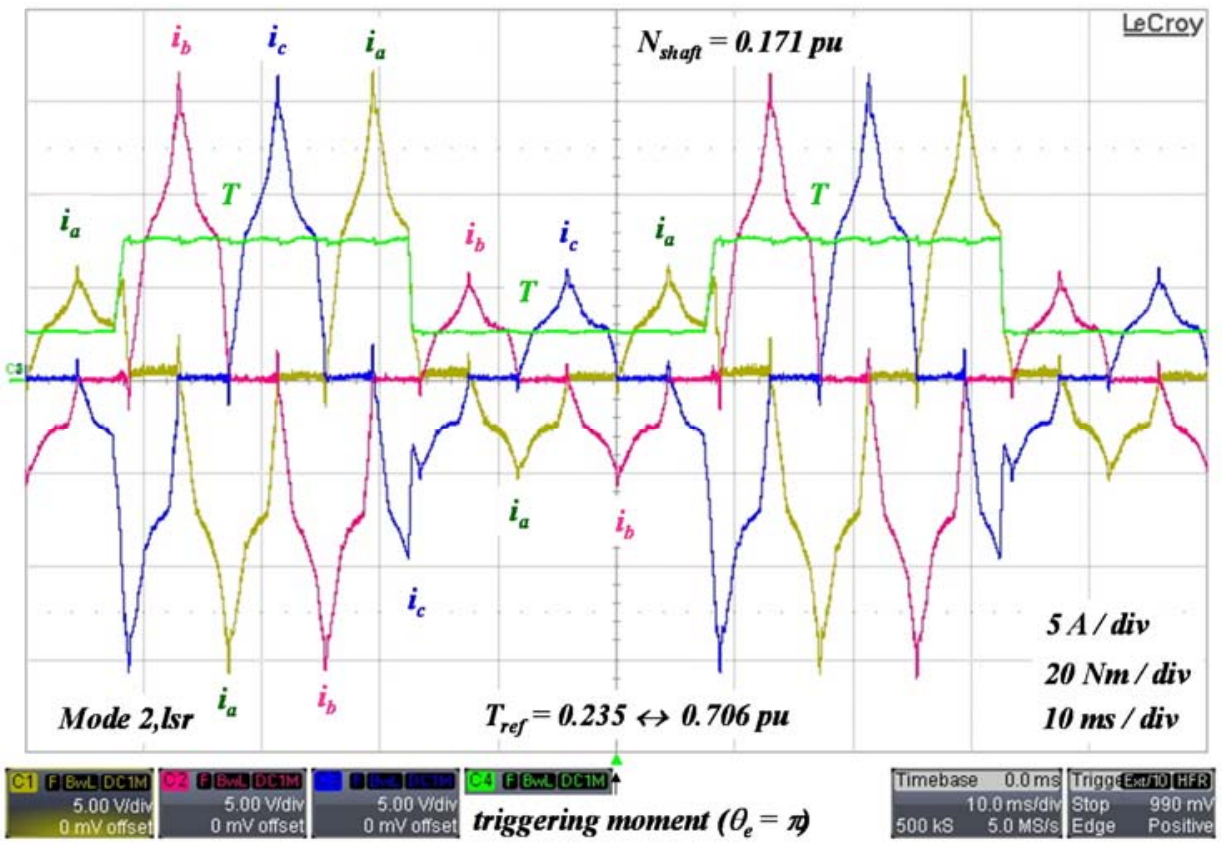

Fig. 18 : 3-phase current and related torque in Mode 2,Isr while tracking torque reference

6 Remaining in steady state operation, the four different mode operation have been assessed at

7 different torque demands and using a constant speed. Results are illustrated in Fig. 19 in the case 8 of $N=150 \mathrm{rmin}^{-1}$. The four solid lines represent the measured overall losses, in each mode in

9 the case of effective current lower than the motor rated value. Measures beyond the rated value 10 are also displayed using magenta circles (Mode 1), blue crosses (Mode 2), green stars 11 (Mode 2,slr) and red triangles (Mode 3). The classic mode is tested too but is not shown here, 12 since its losses are very close to those of Mode 3. 
Accepted article for publication in a future issue of ELSEVIER Electric Power Systems Research - Citation information: 10.1016/j.epsr.2016.09.014.

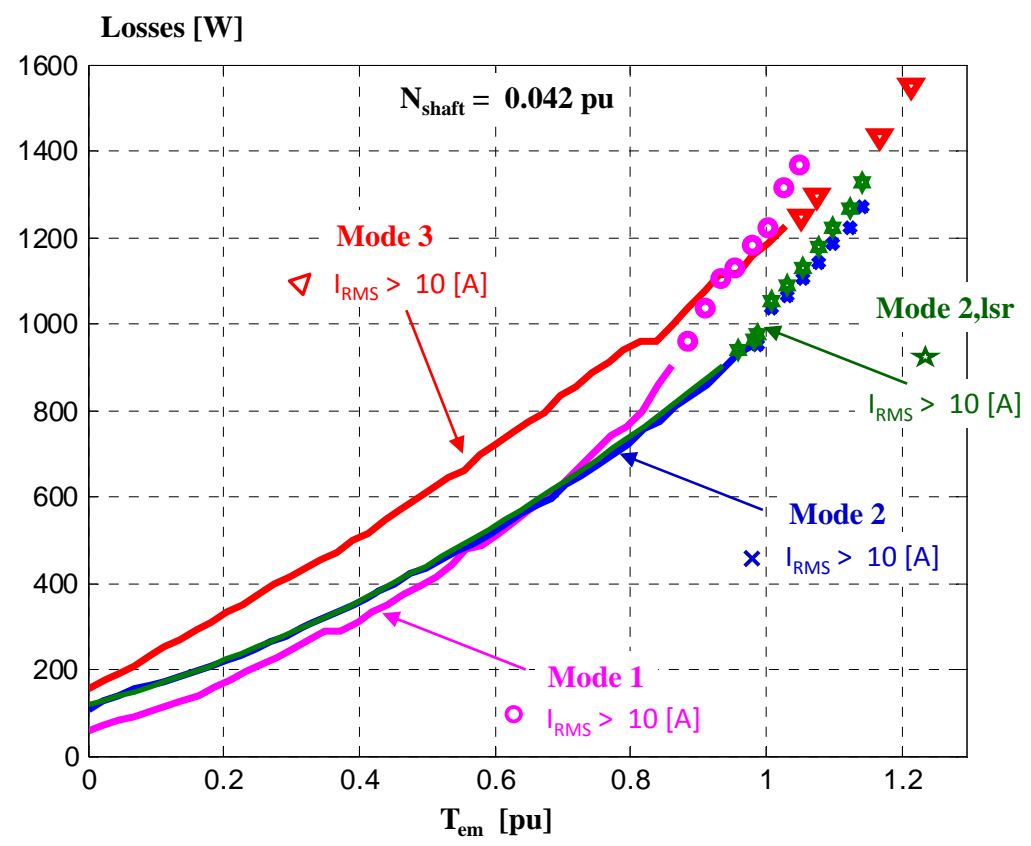

Fig. 19 : PMSM drive overall losses in the 4 suggested modes at constant speed (@N = $150 r \min ^{-1}$ ).

4 It may be observed that for low torques, total losses are greater when more phases operate. Thus,

5 under these operating conditions, the mode that appears best for good performance in term of 6 power losses is the Mode 1. This confirms the theoretical results. However, the use of Mode 1

7 involves more quadratic losses in comparison with the other two modes of operation. Therefore 8 overall losses in Mode 2 become lower than in Mode 1 above a threshold value of 0.65 pu. 9 Above this middle-value, it is better to select Mode 2,slr. Indeed Mode 2,lsr presents similar 10 losses to those of Mode 2, except in high current RMS values. Mode 2,lsr also produces a slightly 11 smaller torque at the rated current level. These features are not surprising, given the fact that the 12 number of phases conducting simultaneously is identical and the current waveforms are roughly 13 similar. The partial discrepancy leads to a slightly higher RMS value for Mode 2,slr than for 14 Mode 2. Conversely it also enables to use Mode 2,slr at higher speed which is indeed a definite 15 advantage to this latter suggested mode. In addition, because of the rated current $(10 \mathrm{~A})$, the 
Accepted article for publication in a future issue of ELSEVIER Electric Power Systems Research - Citation information: 10.1016/j.epsr.2016.09.014.

1 maximum torque value achieved in Mode 1 is limited to $0.85 \mathrm{pu}$, whereas Mode 2 enables

$20.97 \mathrm{pu}$ and Mode 3 reaches $1.03 \mathrm{pu}$. Losses in Mode 3 change almost linearly with torque

3 increments. To discern the intersection of the curves corresponding to Mode 2 and Mode 3, it is

4 necessary for the current in the phases to exceed the rated value.

5 Surprisingly, losses in Mode 3 are higher than expected. Indeed, for high-load, where quadratic

6 losses are dominant, Mode 2 and Mode 3 were expected to lead to very similar losses. However,

7 in Mode 3, the three phases of the machine are fed simultaneously, currents in the machine are

8 therefore defined by the response of two equivalent fictitious machines, namely the main

9 machine and the zero-sequence machine. As the zero-sequence inductance is low (roughly a tenth

10 of the phase self-inductance), the machine is, in Mode 3, subject to higher currents at the

11 switching frequency, due to zero-sequence voltages generated by the inverter, and therefore this

12 mode leads to much higher losses than in the two other modes. However, it may be noted that

13 Mode 3 is mandatory to implement high torques.

\section{5. Conclusion And Perspectives}

15 This paper studies the combination of a 3-phase open-end winding synchronous machine and a

$163 \mathrm{H}$-bridge inverter. This motor drive architecture, covered by several patents owned by VALEO

17 group, provides degrees of freedom. One of its principal characteristics is its capability to be fault

18 tolerant.

19 The original feature in the innovative approach is based on the optimization of the drive normal

20 operation mode. It makes better use of the architecture degrees of freedom. The idea consists in

21 adjusting the number of phases in use to the demanded torque. By so doing, the power efficiency

22 at low torque operating points has been increased significantly. For instance, at half rated torque

$23(21.25 \mathrm{Nm})$ the global losses have been diminished by one-third (Fig. 19). 
Accepted article for publication in a future issue of ELSEVIER Electric Power Systems Research - Citation information: 10.1016/j.epsr.2016.09.014.

1 The optimization method is based on the control-oriented model of the synchronous machine. It

2 relies on a general approach using the Euler-Lagrange method. The result is an analytical solution

3 and is easy to adjust to various synchronous motors because it is based on a generic formulation.

4 An experimental setup enables to validate the theoretical considerations. First, it allows to prove

5 that the drive control scheme is able to track the innovative optimal current references in each of

6 the three proposed modes. Overall losses measurements show the benefit of Mode 1 for low

7 torques and Mode 2 for middle torques. Mode 3 is very close to basic sinusoidal mode and allows

8 to produce high torques.

9 A future work perspective is to better understand the impact of the various PWM vector

10 modulations on the drive overall losses and design an energy management strategy. Additionally,

11 future research should focus on the PMSM local behavior while operating in Modes 1 or 2 at high

12 current rms value. The issue is that it has to be ascertained whether there are no local core

13 saturation and possibly refine the PMSM design accordingly. At this stage of the analysis, only

14 large-scale phenomena can be observed. Looking at losses, torque response and voltage 15 waveforms show no core saturation. This further study will specify this issue and identify 16 remedial action for developing a final product.

6. REFERENCES

19 [1] Lee Woojoo, Wang Yanzhi, Shin Donghwa, N. Chang, M. Pedram, Optimizing the Power 20 Delivery Network in a Smartphone Platform, IEEE Trans. Comput.-Aided Design Integr. 21 Circuits Syst. 33 (1) (2014) 36 - 49. DOI: 10.1109/TCAD.2013.2282287 
Accepted article for publication in a future issue of ELSEVIER Electric Power Systems Research - Citation information: 10.1016/j.epsr.2016.09.014.

1 [2] D.C. Kilper, G. Atkinson, S.K. Korotky, S. Goyal, P. Vetter, D. Suvakovic, O. Blume, Power Trends in Communication Networks, IEEE J. Sel. Topics Quantum Electron. 17 (2) (2011) 275 - 284. DOI: 10.1109/JSTQE.2010.2074187

[3] E. Candan, P. S. Shenoy, R.C.N. Pilawa-Podgurski, “A Series-Stacked Power Delivery Architecture with Isolated Differential Power Conversion for Data Centers", IEEE Trans. on Power Electron. 31 (5) (2016) 3690 - 3703. DOI: 10.1109/TPEL.2015.2464805

[4] O. Beik, N. Schofield, An Off-Shore Wind Generation Scheme With High Voltage Hybrid Generator, HVDC Interconnections and Transmission, IEEE Trans. Power Del., Year: 2015, Volume: PP, Issue: 99. DOI: 10.1109/TPWRD.2015.2492472

[5] T.V. Thang, N.M. Thao, Jong-Ho Jang, Joung-Hu Park, Analysis and Design of GridConnected Photovoltaic Systems With Multiple-Integrated Converters and a Pseudo-DCLink Inverter, IEEE Trans. Ind. Electron. 61 (7) (2014) 3377 - 3386. DOI: 10.1109/TIE.2013.2281153

[6] Jasem Khajesalehi, Mohsen Hamzeh, Keyhan Sheshyekani, Ebrahim Afjei, Modeling and control of quasi Z-source inverters for parallel operation of battery energy storage systems: Application to microgrids, Electric Power Syst. Res. 125 (2015) 164-173. doi:10.1016/j.epsr.2015.04.004

[7] K. Muta, M. Yamazaki, and J. Tokieda, Development of new-generation hybrid system THS II—Drastic improvement of power performance and fuel economy, SAE Tech. Rep., no. 2004-01-0064, 2004. DOI: 10.4271/2004-01-0064

[8] J.W Kolar, F. Krismer, Y. Lobsiger, J. Muhlethaler, T. Nussbaumer, J. Minibock, Extreme efficiency power electronics, in Proc. 7th International Conference on Integrated Power Electronics Systems (CIPS 2012), pp.1-22, 6-8 March 2012 
Accepted article for publication in a future issue of ELSEVIER Electric Power Systems Research - Citation information: 10.1016/j.epsr.2016.09.014.

1 [9] B. Sahan, S. V. Araujo, C. Nöding, and P. Zacharias, Comparative evaluation of threephase current source inverters for grid interfacing of distributed and renewable energy systems, IEEE Trans. Power Electron. 26 (8) (2011) 2304-2318. DOI: 10.1109/TPEL.2010.2096827

[10] Falk, M. Meinhardt, and V. Wachenfeld, Efficiency and grid compatibility of photovoltaic inverters - state-of-the-art and future trends, in Proc. of the Power Conversion and Intelligent Motion Conf. (PCIM Europe), Nuremberg, Germany, May 2009, pp. 14-20. DOI: 10.1049/iet-rpg.2015.0101

[11] Oleksandr Husev, Carlos Roncero-Clemente, Enrique Romero-Cadaval, Dmitri Vinnikov, Tanel Jalakas, Three-level three-phase quasi-Z-source neutral-point-clamped inverter with novel modulation technique for photovoltaic application, Electric Power Syst. Res. 130 (2016) 10-21. doi:10.1016/j.epsr.2015.08.018

[12] J. Whitney and P. Delforge, Data center efficiency assessment, Natural Resources Defense Council, Tech. Rep., Aug. 2014.

[13] M. Kasper, Chen Cheng-Wei, D. Bortis, J.W.Kolar, G. Deboy, Hardware verification of a hyper-efficient $(98 \%)$ and super-compact $(2.2 \mathrm{~kW} / \mathrm{dm} 3)$ isolated $\mathrm{AC} / \mathrm{DC}$ telecom power supply module based on multi-cell converter approach, in Proc. Applied Power Electronics Conference and Exposition (APEC), 2015, Pages: 65 - 71, DOI: 10.1109/APEC.2015.7104333

[14] J. Kolar, What are the Big Challenges in Power Electronics, in Proc. Of 8th International Conference on Integrated Power Electronic Systems (CIPS) Keynote presentation, 2014

[15] J. Biela, S. Waffler, J.W. Kolar, Mission profile optimized modularization of hybrid vehicle DC/DC converter systems, in Proc. IEEE 6th International Power Electronics and 
Accepted article for publication in a future issue of ELSEVIER Electric Power Systems Research - Citation information: 10.1016/j.epsr.2016.09.014.

Motion Control Conference (IPEMC '09.), 2009, Pages: 1390 - 1396, Wuhan, China, May 2009, DOI: 10.1109/IPEMC.2009.5157601 .

[16] A. Merkert, T. Krone, A. Mertens, Characterization and Scalable Modeling of Power Semiconductors for Optimized Design of Traction Inverters with Si- and SiC-Devices, IEEE Trans. on Power Electron. 29 (5) (2014) 2238 - 2245, DOI: 10.1109/TPEL.2013.2294682.

[17] C.N.-M.Ho, H. Breuninger, S. Pettersson, G. Escobar, Francisco Canales, A Comparative Performance Study of an Interleaved Boost Converter Using Commercial $\mathrm{Si}$ and $\mathrm{SiC}$ Diodes for PV Applications, IEEE Trans. on Power Electron. 28 (1) (2013), 289 - 299. DOI: 10.1109/TPEL.2012.2197830.

[18] T. Azib, O.Bethoux, C. Marchand, E. Berthelot, An Innovative Control Strategy of a Single Converter for Hybrid Fuel Cell/Supercapacitor Power Source, IEEE Trans. Ind. Electron. 57 (12) (2010) 4024 - 4031. DOI: 10.1109/TIE.2010.2044123

[19] S.Gunther,S. Ulbrich, W. Hofmann, Driving cycle-based design optimization of interior permanent magnet synchronous motor drives for electric vehicle application, in Proc. International Symposium on Power Electronics, Electrical Drives, Automation and Motion (SPEEDAM), 2014, Pages: 25 - 30. DOI: 10.1109/SPEEDAM.2014.6872108

[20] M. Hage Hassan, G. Remy, G. Krebs and C. Marchand, Radial output space mapping for electromechanical systems design, COMPEL: The International Journal for Computation and Mathematics in Electrical and Electronic Engineering, Vol. 33 No. 3, 2014, pp. 965 975, ISSN: 0332-1649.

[21] Julio Cesar Rosas-Caro, Jonathan Carlos Mayo-Maldonado, Antonio ValderrabanoGonzalez, Francisco Beltran-Carbajal, Juan Manuel Ramirez-Arredondo, Juan Ramon 
Accepted article for publication in a future issue of ELSEVIER Electric Power Systems Research - Citation information: 10.1016/j.epsr.2016.09.014.

Rodriguez-Rodriguez, DC-DC multiplier boost converter with resonant switching, Electric Power Syst. Res. 119 (2015) 83-90. doi:10.1016/j.epsr.2014.09.003.

[22] Rui Ling, Guoyan Zhao, Qin Huang, High step-up interleaved boost converter with low switch voltage stress, Electric Power Systems Research, Volume 128, November 2015, Pages 11-18. doi:10.1016/j.epsr.2015.06.016

[23] Y. Ayoubi, M. Elsied, A. Oukaour, H. Chaoui, Y. Slamani, H. Gualous, Four-phase interleaved DC/DC boost converter interfaces for super-capacitors in electric vehicle application based on advanced sliding mode control design, Electr. Power Syst. Res. 134 (2016) 186-196. DOI: 10.1016/j.epsr.2016.01.06

[24] J.D. van Wyk, F.C. Lee, Liang Zhenxian, R. Chen, Wang Shuo, Lu Bing, Integrating active, passive and EMI-filter functions in power electronics systems: a case study of some technologies, IEEE Trans. on Power Electron. 20 (3) (2005) 523 - 536. Doi: 10.1109/TPEL.2005.846553.

[25] J.W. Kolar, F. Krismer,Y. Lobsiger, J. Muhlethaler, T. Nussbaumer, J. Minibock, Extreme efficiency power electronics, 7th International Conference on Integrated Power Electronics Systems (CIPS2012), 2012, pp. 1 - 22

[26] Jen-Ta Su, Chih-Wen Liu, A Novel Phase-Shedding Control Scheme for Improved Light Load Efficiency of Multiphase Interleaved DC-DC Converters, IEEE Trans. on Power Electron. 28 (10) (2013) 4742 - 4752. DOI: 10.1109/TPEL.2012.2233220.

[27] “LP8754 Multi-Phase Six-Core Step-Down Converter", Texas Instrument datasheet, SNVS861A -February 2014-REVISED August 2014, http://www.ti.com/lit/ds/symlink/lp8754.pdf. 
Accepted article for publication in a future issue of ELSEVIER Electric Power Systems Research - Citation information: 10.1016/j.epsr.2016.09.014.

1 [28] Hasuka, Y., Sekine, H., Katano, K., and Nonobe, Y., Development of Boost Converter for MIRAI, SAE Technical Paper, 2015-01-1170, 2015, doi:10.4271/2015-01-1170.2.

[29] P. Zumel, C. Fernandez, C.; A. de Castro, O. Garcia, Efficiency improvement in multiphase converter by changing dynamically the number of phases, in Proc 37 th IEEE Power Electronics Specialists Conference (PESC '06), 2006, pp. 1 - 6, DOI: 10.1109/PESC.2006.1712202.

[30] A.V. Peterchev, J. Xiao, S.R. Sanders, Architecture and IC implementation of a digital VRM controller, IEEE Trans. on Power Electron. 18 (1) (2003) 356-364. doi: 10.1109/TPEL.2002.807099.

[31] L. De Sousa and B. Bouchez, Combined Electric Device for Powering and Charging, US Patent 20110221363 A1, Sept. 15, 2011.

[32] L. De Sousa and B. Bouchez, Method and Electric Combined Device for Powering and Charging with Compensation Means, US Patent 20120019173 A1, Jan. 26, 2012.

[33] L. De Sousa, B. Bouchez, and J. L. Da Costa, Method of exchanging electrical energy between an electrical network conveying a dc or ac electrical quantity and an electrical energy storage unit for hybrid or electric vehicle, European Patent EP2794343 A2, Oct. $29,2014$.

[34] B. Bouchez and L. De Sousa, Charge transfer device and associated management method, US Patent US20140042807 A1, Feb. 13, 2014.

[35] M. Naidu and S. Gopalakrishnan, "Fault-tolerant permanent magnet motor drive topologies for automotive X-By-wire systems", IEEE Transactions on Industry Applications, vol. 46, no. 2, pp. 841-848, Mar./Apr. 2010. 
Accepted article for publication in a future issue of ELSEVIER Electric Power Systems Research - Citation information: 10.1016/j.epsr.2016.09.014.

1 [36] A. Bruyère, L. De Sousa, B. Bouchez, P. Sandulescu, X. Kestelyn, E. Semail, A multiphase traction/fast-battery-charger drive for electric or plug-in hybrid vehicles: Solutions for control in traction mode, in Proc. VPPC 2010, 2000, Lille, pp. 1-7. DOI: 10.1109/VPPC.2010.5729220

[37] P. Sandulescu, F. Meinguet, X. Kestelyn, E. Semail, A. Bruyere, Control Strategies for Open-End Winding Drives Operating in the Flux-Weakening Region, IEEE Trans. on Power Electron. 29 (9) (2014) 4829 - 4842. DOI: 10.1109/TPEL.2013.2283107

[38] S. Lacroix, E. Labouré, and M. Hilairet, An integrated fast battery charger for electric vehicle, in Proc. VPPC 2010, 2010, Lille, pp. 1-6. DOI: 10.1109/VPPC.2010.5729063

[39] F. Meinguet, P. Sandulescu, X. Kestelyn, E. Semail, A Method for Fault Detection and Isolation Based on the Processing of Multiple Diagnostic Indices: Application to Inverter Faults in AC Drives, IEEE Trans. Veh. Technol. 62 (3) (2013) 995 - 1009. DOI: 10.1109/TVT.2012.2234157

[40] S. Diao, D. Diallo, Z. Makni, C. Marchand, J. -F. Bisson, "A Differential Algebraic Estimator for Sensorless Permanent-Magnet Synchronous Machine Drive”, IEEE Trans. Energy Convers. 30 (1) 82 - 89. DOI: 10.1109/TEC.2014.2331080

[41] A. Kolli, O. Bethoux, A. De Bernardinis, E. Laboure, G. Coquery, Space-Vector PWM Control Synthesis for an H-Bridge Drive in Electric Vehicles, IEEE Trans. Veh. Technol. 62 (6) (2013) 2441 - 2452. DOI: 10.1109/TVT.2013.2246202

[42] T.A. Lipo et al., Analysis of Synchronous Machines, Second Edition, ISBN 978-1-43988067-8, CRC Press, June 2012 
Accepted article for publication in a future issue of ELSEVIER Electric Power Systems Research - Citation information: 10.1016/j.epsr.2016.09.014.

1 [43] Intersil, ISL78225 datasheet, 4-Phase Interleaved Boost PWM Controller with Light Load Efficiency Enhancement, http://www.intersil.com/content/dam/Intersil/documents/isl7/is178225.pdf

4 [44] L. E. Elsgolc, Calculus of variations, Addison-Wesley Publishing company, 1962.

[45] D. S. Naidu, Calculus of Variations and Optimal Control, in Optimal control systems, August 27, 2002 by CRC Press, USA: Florida.

[46] Jean-Yves Dieulot, Fréderic Colas, Lamine Chalal, Geneviève Dauphin-Tanguy, Economic supervisory predictive control of a hybrid power generation plant, Electr. Power Syst. Res. 127 (2015) 221-229. doi:10.1016/j.epsr.2015.06.006.

10 [47] Faa-Jeng Lin, Hsin-Jang Shieh, Kuo-Kai Shyu, Po-Kai Huang, On-line gain-tuning IP 11 controller using real-coded genetic algorithm, Electr. Power Syst. Res. 72 (2) (2004) 15712 169, doi:10.1016/j.epsr.2004.03.013. 